\title{
Early Formation of GABAergic Synapses Governs the Development of Adult-Born Neurons in the Olfactory Bulb
}

\author{
Marta Pallotto, ${ }^{1,2,3}$ Antoine Nissant, ${ }^{2,3}$ Jean-Marc Fritschy, ${ }^{4}$ Uwe Rudolph, ${ }^{5,6}$ Marco Sassoè-Pognetto, ${ }^{1}$ \\ Patrizia Panzanelli, ${ }^{1}$ and Pierre-Marie Lledo ${ }^{2,3}$ \\ ${ }^{1}$ Department of Anatomy, Pharmacology, and Forensic Medicine and National Institute of Neuroscience-Italy, University of Turin, I-10126 Turin, Italy, \\ ${ }^{2}$ Institut Pasteur, Laboratory for Perception and Memory, Department of Neurosciences, F-75015 Paris, France, ${ }^{3}$ Centre National de la Recherche \\ Scientifique, Unité de Recherche Associée 2182, F-75015 Paris, France, ${ }^{4}$ Institute of Pharmacology and Toxicology, University of Zurich and Neuroscience \\ Center Zurich, CH-8057 Zurich, Switzerland, and ${ }^{5}$ Laboratory of Genetic Neuropharmacology, McLean Hospital and ${ }^{6}$ Department of Psychiatry, Harvard \\ Medical School, Belmont, Massachusetts 02478-1064
}

In mammals, olfactory bulb granule cells (GCs) are generated throughout life in the subventricular zone. GABAergic inputs onto newborn neurons likely regulate their maturation, but the details of this process remain still elusive. Here, we investigated the differentiation, synaptic integration, and survival of adult-born GCs when their afferent GABAergic inputs are challenged by conditional gene targeting. Migrating GC precursors were targeted with Cre-eGFP-expressing lentiviral vectors in mice with a floxed gene encoding the GABA receptor $\alpha$-subunit (i.e., Gabra2). Ablation of the $\alpha$ 2-subunit did not affect GC survival but dramatically delayed their maturation. We found a reduction in postsynaptic $\alpha 2$-subunit and gephyrin clusters accompanied by a decrease in the frequency and amplitude of GABAergic postsynaptic currents beginning 14 d post-injection (dpi). In addition, mutant cells exhibited altered dendritic branching and spine density. Spine loss appeared with mislocation of glutamatergic synapses on dendritic shafts and a reduction of spontaneous glutamatergic postsynaptic currents, underscoring the relevance of afferent GABAergic transmission for a proper synaptic integration of newborn GCs. To test the role of GABAergic signaling during much early stages of GC maturation, we used a genetic strategy to selectively inactivate Gabra2 in precursor cells of the subventricular zone. In these mice, labeling of newborn GCs with eGFP lentiviruses revealed similar morphological alterations as seen on delayed Gabra2 inactivation in migrating neuroblasts, with reduced dendritic branching and spine density at $7 \mathrm{dpi}$. Collectively, these results emphasize the critical role of GABAergic synaptic signaling for structural maturation of adult-born GCs and formation of glutamatergic synapses.

\section{Introduction}

Adult neurogenesis is a unique form of structural plasticity that sculpts preexisting circuit function through the continuous addition and removal of newly formed neurons. Importantly, the impact of this process depends on the overall synaptic activity of the preexisting circuit (Kelsch et al., 2010; Ming and Song, 2011). As a result, some of the most important parameters regulating

Received Jan. 16, 2012; revised April 6, 2012; accepted April 27, 2012.

Author contributions: J.-M.F., M.S.P., and P.-M.L. designed research; M.P., A.N., and P.P. performed research; U.R. contributed unpublished reagents/analytic tools; M.P., A.N., J.-M.F., M.S.P., P.P., and P.-M.L. analyzed data; J.-M.F., M.S.P., P.P., and P.-M.L. wrote the paper.

The Lledo laboratory was supported by the life insurance company Novalis Taitbout, the Fondation pour la Recherche Médicale, the Laboratory for Excellence Programme Revive, Agence Nationale de la Recherche Grants ANR-BLAN-SVSE4-LS-110624 and ANR-09-NEUR-004 in the frame of ERA-NET NEURON of the FP7 program by the European Commission. M.P. is the recipient of fellowships sponsored by Università Italo-Francese and Institut Servier, J.-M.F. by Swiss National Science Foundation Grant 31003A_130495, PP by Compagnia di San Paolo Grant 2008-2254, and M.S.P. by the Compagnia di San Paolo (2007) and Regione Piemonte (Ricerca Sanitaria Finalizzata 2008/bis). We thank Matt Valley for critical reading of this manuscript and Françoise Lazarini for her help in transferring the mouse lines at the Pasteur Institute Animal facility.

Correspondence should be addressed to either of the following Dr. Pierre-Marie Lledo, Institut Pasteur, Perception and Memory Laboratory, 25 rue du Dr. Roux, F-75724 Paris Cedex 15, France, E-mail: pmlledo@pasteur.fr; or Dr. Marco Sassoè-Pognetto, Department of Anatomy, Pharmacology, and Forensic Medicine, University of Turin, and Istituto Nazionale di Neuroscienze, Corso Massimo d'Azeglio 52, I-10126 Turin, Italy, E-mail:marco.sassoe@unito.it. DOI:10.1523/JNEUROSCI.0214-12.2012

Copyright $\odot 2012$ the authors $\quad 0270-6474 / 12 / 329103-13 \$ 15.00 / 0$ adult neurogenesis are guided by the properties of the early synapses impinging onto developing adult-born neurons. The mechanisms that link synaptogenesis with morphological differentiation and functional maturation of the newcomers are particularly interesting because it means that some of the major forces driving synaptic plasticity also act on the long-term survival of adult-born neurons (Yamaguchi and Mori, 2005; Whitman and Greer, 2007; Kelsch et al., 2008; Nissant et al., 2009).

Neurogenic niches persist in the dentate gyrus of the hippocampus and the subventricular zone (SVZ) of the adult mammal brain (Altman, 1969; Alvarez-Buylla and Garcia-Verdugo, 2002; Kempermann et al., 2004). Neuroblasts generated in the SVZ migrate along the rostral migratory stream (RMS) to reach the olfactory bulb (OB), in which they differentiate as granule cells (GCs) and periglomerular cells and integrate functionally over several weeks (Lledo et al., 2006). GCs are axonless GABAergic interneurons; their apical dendrites extend radially into the external plexiform layer (EPL) and grow spines that establish reciprocal synapses with the dendrites of mitral cells and tufted cells (Shepherd et al., 2007). In addition, GCs receive axodendritic excitatory synapses, as well as inhibitory synapses from local microcircuits. GABAergic signaling regulates early steps of adult neurogenesis (Platel et al., 2008; Ming and Song, 2011); however, its impact on the maturation and synaptic integration 
Table 1. Primary antibodies used in this study

\begin{tabular}{|c|c|c|c|c|}
\hline Protein target & Species & Dilution & Source; catalog\# & Reference \\
\hline Doublecortin & Guinea pig & $1: 2000$ & Millipore Bioscience Research Reagents; AB2253 & Waclaw et al., 2006 \\
\hline Gephyrin & Mouse & $1: 1000$ & Synaptic Systems; mAb7a; 147711 & Panzanelli et al., 2009 \\
\hline \multirow[t]{2}{*}{ GFP } & Rabbit & $1: 2000$ & Synaptic Systems; 132002 & \multirow[t]{2}{*}{ Panzanelli et al., 2009; Duveau et al., 2011} \\
\hline & Chicken & $1: 5000$ & Aves Laboratories; GFP-1020 & \\
\hline GAD65 & Mouse & $1: 1000$ & Developmental Studies Hybridoma Bank, University of lowa; GAD-6 & Chang and Gottlieb, 1988 \\
\hline $\mathrm{GABA}_{\mathrm{A}} \mathrm{R} \alpha 2$-subunit & Guinea pig & $1: 1000$ & Self-made & Panzanelli et al., 2011 \\
\hline $\mathrm{GABA}_{\mathrm{A}} \mathrm{R} \alpha 3$-subunit & Guinea pig & $1: 8000$ & Self-made & Panzanelli et al., 2011 \\
\hline PSD95 & Mouse & $1: 1000$ & University of California, Davis/National Institutes of Health NeuroMab; 75-028 & Panzanelli et al., 2009 \\
\hline Tyrosine hydroxylase & Mouse & $1: 4000$ & Immunostar; 22941 & Holderith et al., 2003 \\
\hline
\end{tabular}

of newborn GCs is unknown. Recently, we have demonstrated that newborn GCs form functional GABAergic and glutamatergic synapses shortly after entering the $\mathrm{OB}$, with an initial predominance of GABAergic synapses (Panzanelli et al., 2009; Katagiri et al., 2011). This observation raises the possibility that GABAergic synaptic transmission regulates the morphological and functional maturation of GCs, which has been previously shown to be controlled by activity-dependent mechanisms (Kelsch et al., 2010; Ming and Song, 2011).

We took advantage of the selective expression of $\alpha 2$-subunit containing $\mathrm{GABA}_{\mathrm{A}}$ receptors $\left(\mathrm{GABA}_{\mathrm{A}} \mathrm{Rs}\right)$ in GCs (Panzanelli et al., 2009) to irreversibly alter synaptic GABAergic inputs in adultborn GCs through two distinct means. First, cell-specific Gabra2 ablation was done in neuroblasts migrating to the OB by injecting a lentiviral vector encoding Cre-eGFP into the RMS of mice carrying floxed Gabra2 alleles. The morphological development of mutant GCs and formation of functional synapses were analyzed with immunohistochemistry and electrophysiology. These experiments revealed impaired GABAergic synaptic responses in mutant cells and striking defects in dendritic development and spine formation, without changing GC survival. The impact of Gabra2 inactivation on plasticity produced by chronic olfactory deprivation and enrichment was tested to indicate any possible interaction between GABAergic synaptic transmission and the experience-sensitive regulation of GC development. Second, using the Tet-on system in double-transgenic mice, Gabra2 was deleted in progenitor cells expressing the glial-specific glutamate transporter (GLAST), yielding results comparable with those gained with floxed Gabra2 mice. Collectively, these data reveal that early GABAergic synaptic transmission controls the activitydependent development of adult-born GC and influences their synaptic integration into preexisting networks.

\section{Materials and Methods}

\section{Animals}

All experiments were conducted in accordance with the European Communities Council Directive of November 24, 1986 (86/609/EEC) and with institutional approval. The generation of mice carrying the gene for Gabra2 flanked by LoxP sites (hereafter called $\alpha 2$-FL) has been described previously (Witschi et al., 2011). These transgenic mice were backcrossed on the C57BL/6J background for more than nine generations. Homozygous $\alpha 2$-FL mice were used for conditional deletion of Gabra2 by CreeGFP lentiviral transduction of neuroblasts migrating through the RMS, with wild-type (WT) mice as control. In a second series of experiments, $\alpha 2^{\mathrm{fl} / \mathrm{fl}}$-GLAST::CreERT2 ${ }^{+/-}$transgenic mice were obtained by crossmating GLAST::CreERT2 mice (a gift from Prof. Magdalena Götz, Ludwig-Maximilians-Universität München, Germany; see Mori et al., 2006) with $\alpha 2$-FL mice. In these double-mutant mice, hereafter called $\alpha 2$-GLAST, Gabra2 deletion was induced in GLAST-expressing $\left(\mathrm{GLAST}^{+}\right.$) progenitor cells during systemic tamoxifen (Tam) administration. Control mice were injected with vehicle [corn oil (Oil)]. Mice were housed under a $12 \mathrm{~h}$ light/dark cycle, with food and water available ad libitum.

\section{Lentiviral vectors}

A replication-deficient lentiviral vector was used to express Cre recombinase and eGFP in newborn GCs of $\alpha 2$-FL and WT control mice. We used a plasmid generously provided by Tyler Jacks (Addgene, Cambridge, MA) (Plasmid 20781: UbC-GFP.PGK-Cre vector). The concentration of lentiviral vector particles used was $115 \mathrm{ng}$ of $\mathrm{p} 24$ per microliter (the p24 protein is a nucleocapsid protein used as an important early marker of HIV infection). Average vector titers were in the order of $10^{9}$ transduction units per milliliter. For visualization of eGFP in newborn GC of $\alpha 2$-GLAST mice, we used a custom-built lentivirus driven by the phosphoglycerate kinase (PGK) promoter as described previously (Grubb et al., 2008).

\section{Stereotaxic injections}

Adult male mice, 8 to 12 weeks old at the time of virus injection, were used for morphological analyses $(n=94)$ and electrophysiological recordings $(n=48)$. Mice were anesthetized with an intraperitoneal injection of xylazine (Rompun; Bayer Health Care) and ketamine (Imalgene; Merial) dissolved in PBS at a dose of 10 and $120 \mathrm{mg} / \mathrm{kg}$ respectively, and mounted on a stereotaxic apparatus (David Kopf Instruments). We performed bilateral injections into the RMS at the following coordinates, using bregma as reference: mediolateral, $\pm 0.82 \mathrm{~mm}$; anteroposterior, $+3.3 \mathrm{~mm}$; and $-2.90 \mathrm{~mm}$ from the pial surface (Panzanelli et al., 2009). Viral vector particles $(200 \mathrm{nl})$ were injected using nanoliter injector Nanoject II (Drummond Scientific) with a glass micropipette at a rate of $23 \mathrm{nl} / \mathrm{s}$. Animals were killed at the indicated survival times after virus injection (in which dpi is days post-injection).

\section{Olfactory enrichment and deprivation}

Chemical ablation of olfactory epithelium. Seven days after lentivirus injection, $\alpha 2$-FL and WT mice were given one intraperitoneal injection of dichlobenil (2,6-dichlobenzonitrile, $25 \mu \mathrm{g} / \mathrm{g}$ body weight; Fluka) in dimethylsulfoxide ( $2 \mu \mathrm{l} / \mathrm{g}$ body weight) or vehicle as control as described previously (Vedin et al., 2004). Mice were killed at $30 \mathrm{dpi}$. The efficacy of this sensory deafferentation protocol was confirmed by assessing the decrease of tyrosine hydroxylase immunoreactivity in the glomerular layer of the OB (data not shown; but see Stone et al., 1991).

Olfactory enrichment. Starting $7 \mathrm{~d}$ after viral injection, mice were exposed daily to three different aromatic fragrances during 3 weeks (Rochefort et al., 2002). The odorants were placed inside a tea ball hanging from the cage roof. In the control group, empty tea balls were placed in the cage. The substances used have been listed by Alonso et al. (2008). Mice were killed for analysis after $30 \mathrm{dpi}$.

\section{Tissue processing for immunohistochemistry}

Two different protocols were used for optimal detection of the markers.

Quickly fixed tissue. Mice were deeply anesthetized (sodium pentobarbital; $50 \mathrm{mg} / \mathrm{kg}$, i.p.; Sanofi-Aventis) and decapitated. The OB was removed, collected in ice-cold artificial CSF (ACSF), and cut in $300-\mu \mathrm{m}-$ thick horizontal slices with a sliding microtome (VT 1000S; Leica), as described previously (Schneider Gasser et al., 2006). Slices were incubated in oxygenated ACSF for $30 \mathrm{~min}$ at $35^{\circ} \mathrm{C}$, fixed by immersion in $4 \%$ 
A

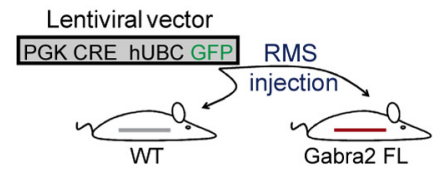

B

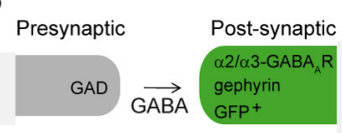

E

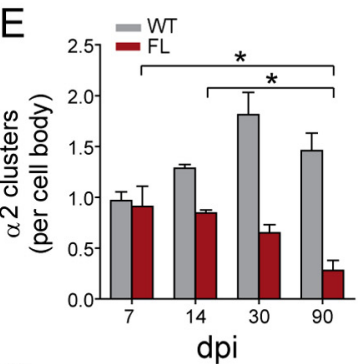

G

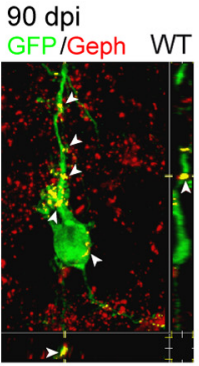

I

90 dpi

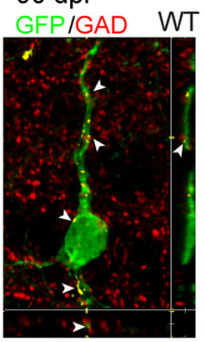

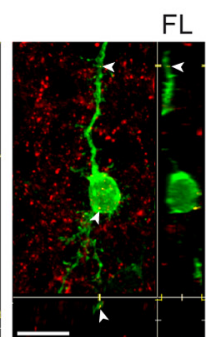
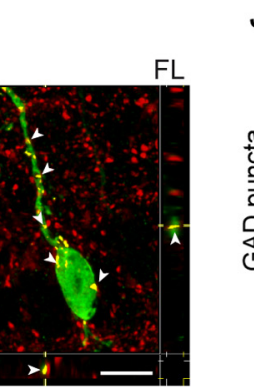

C

$90 \mathrm{dpi}$
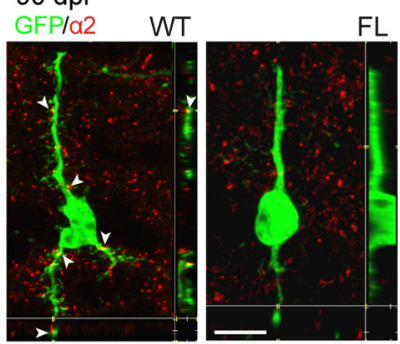

FL

$90 \mathrm{dpi}$
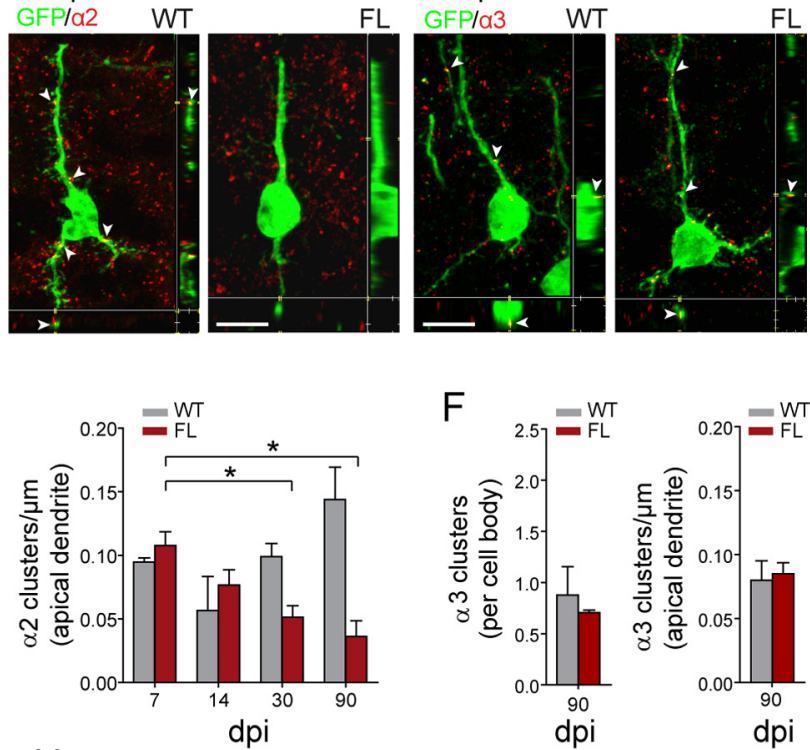

$\mathrm{H}$

F

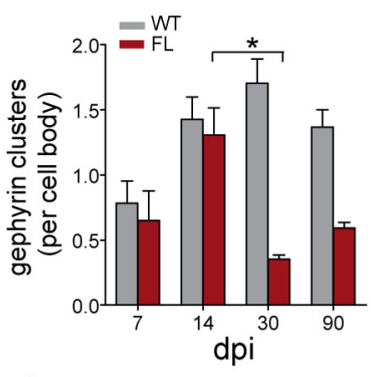

J

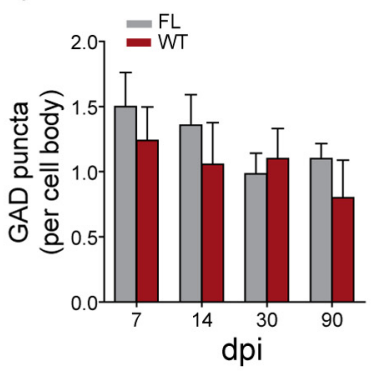

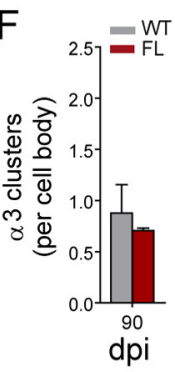
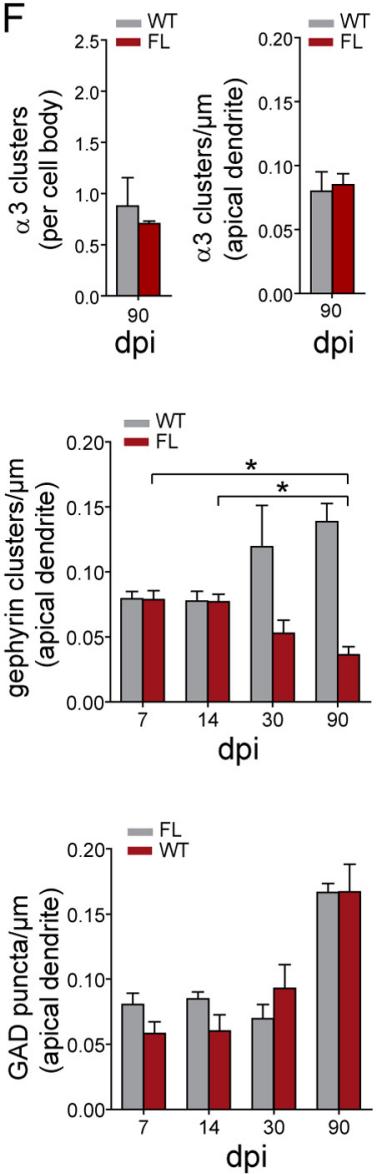

Figure 1. Effects of Cre-mediated deletion of Gabra2 gene in adult-born GCS. A, Schematic diagram of the experimental approach to label adult-born GCs by stereotaxic injection of a lentiviral vector expressing (re recombinase and eGFP into the RMS. Infected cells are readily recognized by eGFP labeling. $\boldsymbol{B}$, Schematic localization of the markers analyzed by immunohistochemistry at GABAergic synapses made on adult-born GCS. C, Images from confocal laser-scanning microscopy depicting the presence of $\alpha 2$-subunit-immunoreactive clusters (red) in eGFP ${ }^{+}$cells of WT and $\alpha 2$-FL mice after $90 \mathrm{dpi}$, confirmed by colocalization analysis (yellow; arrowheads). Note the almost complete disappearance of $\alpha 2$-subunit clusters in adult-born cells of $\alpha 2$-FL mice at this stage. Each image represents a 3-D projection of a stack of confocal layers spaced $0.35 \mu \mathrm{m}$, shown in the three Cartesian planes. D, Images depicting the presence of $\alpha 3$-subunit clusters (red) in eGFP ${ }^{+}$ cells of WT and $\alpha 2$-FL mice after $90 \mathrm{dpi}$, as confirmed by colocalization analysis (yellow, arrowheads). $\boldsymbol{E}, \boldsymbol{F}$, Quantification of $\alpha 2$ - and $\alpha 3$-subunit clusters (mean \pm SEM) in the cell body and apical dendrite of adult-born GCs in WT and $\alpha 2$-FL mice. G, Images of gephyrin clusters (red) in eGFP ${ }^{+}$cells of WT and $\alpha 2$-FL mice after 90 dpi, as confirmed by colocalization analysis (yellow; arrowheads). $\boldsymbol{H}$, Quantification of gephyrin clusters (mean \pm SEM) showing the decreased gephyrin cluster density in cell body and in the apical dendrite in mutant cells at $30-90$ dpi. II Images depicting the presence of GAD65-immunoreactive puncta apposed to eGFP ${ }^{+}$cells (yellow, arrowheads) after 90 dpi in both genotypes. J, Quantification of GAD65 puncta, representing putative synaptic input, onto the cell body and apical dendrite of adult-born GCS (mean \pm SEM). No difference was observed at any time point. ${ }^{*} p<0.05$, one-way ANOVA with posthoctest (for statistical analyses, see Table 2). Scale bars, $10 \mu \mathrm{m}$.

formaldehyde at room temperature for $12 \mathrm{~min}$, cryoprotected in $30 \%$ sucrose, flat frozen, and sectioned with a cryostat (Microm HM 560). The 16 - $\mu$ m-thick cryosections were mounted onto gelatin-coated glass slides and stored at $-20^{\circ} \mathrm{C}$.

Perfused tissue. Mice were anesthetized as above and fixed by intracardial perfusion of PBS, followed by ice-cold $4 \%$ formaldehyde in $0.1 \mathrm{~m}$ sodium phosphate buffer, $\mathrm{pH}$ 7.4. The brains were removed, postfixed in the same fixative overnight, and cryoprotected in $30 \%$ sucrose. The OBs were then frozen with dry ice and cut into 50- $\mu \mathrm{m}$-thick coronal sections with a cryostat. Sections were stored in antifreeze solution (15\% glucose and 30\% ethylene glycol in $50 \mathrm{~mm}$ sodium phosphate buffer, $\mathrm{pH} 7.4)$ at $-20^{\circ} \mathrm{C}$.

\section{Immunofluorescence staining}

Double and triple immunofluorescence was performed by incubating tissue sections in a mixture of primary antibodies raised in different species (Table 1), diluted in PSB with 5\% normal donkey serum (Jackson Immuno 
Research) and $0.05 \%$ Triton X-100. Sections were then washed in PBS, incubated for $30 \mathrm{~min}$ at room temperature in secondary antibodies raised in donkey, and conjugated to Alexa Fluor 488 (Invitrogen), Cy3, or Cy5 (Jackson ImmunoResearch). Finally, the sections were rinsed again and mounted on glass slides using a fluorescence mounting medium (Dako).

\section{Image acquisition and data analysis}

Sections were visualized by confocal laser-scanning microscopy (LSM5 Pascal; Carl Zeiss) using sequential acquisition of separate channels to avoid fluorescence crosstalk. Stacks of confocal sections were acquired with either a $40 \times$ (numerical aperture 1.3 ) or $100 \times$ (numerical aperture 1.4) objective, with the pinhole set at 1 Airy unit. For display, images were processed with the image analysis software Imaris (version 4.3; Bitplane). For quantification of the number of $\mathrm{GABA}_{\mathrm{A}} \mathrm{R}$ subunit, gephyrin, and PSD95 clusters, as well as vesicular GABA transporter-expressing boutons, single confocal layers were used (pixel size, $70-90 \mathrm{~nm}$ ). The colocalization algorithm of Imaris was used with a threshold set $\sim 100$ to determine the presence of clusters in $\mathrm{eGFP}^{+}$structures. All counting was performed manually on dendrite segments measuring $20-50 \mu \mathrm{m}$. The results were averaged per animal, with each group and time point comprising at least three mice.

The dendritic morphology of newborn GCs was analyzed in $50-\mu \mathrm{m}$-thick sections from perfused tissue stained for eGFP. Confocal images of randomly selected deep and superficial GCs were acquired, spaced by $1 \mu \mathrm{m}$ across the entire thickness of the section with a $40 \times$ objective and analyzed with the software NIH Image J 1.34S. Total dendritic length and number of branches were determined on 3-D projections using the NeuronJ plug-in. Sholl analysis was performed with concentric circles spaced $10 \mu \mathrm{m}$ and centered on the cell soma (Sholl Analysis plugin, Anirvan Ghosh Laboratory, University of California, San Diego, La Jolla, CA). For statistical comparison, the area under the curve (AUC) of the resulting function was calculated. Quantifications were performed on 12-15 cells from three mice of each experimental group.

Spine density was determined on apical dendritic segments of $\mathrm{eGFP}^{+}$GCs, including secondary and tertiary branches in the EPL. At least 10 stacks consisting of 10-15 confocal sections were analyzed per animal using NIH ImageJ software. All dendritic protrusions with a clearly recognizable neck connected to the shaft of the dendrite were counted as spines. Measurement of spine density was performed on 3-D-projected image stacks.

\section{Preembedding immunoelectron microscopy}

$\alpha 2$-FL mice were deeply anesthetized with sodium pentobarbital $(50 \mathrm{mg} / \mathrm{kg}$, i.p.) and perfused with $2 \%$ formaldehyde and $0.1 \%$ glutaraldehyde in sodium acetate buffer, $\mathrm{pH}$, for $2 \mathrm{~min}$, followed by $1 \mathrm{~h}$ perfusion with $2 \%$ formaldehyde and $0.1 \%$ glutaraldehyde in 0.1 м borate buffer, pH 9 (Kollo et al., 2008). The brain was taken out and postfixed in the second fixative overnight. Tissue blocks containing the OBs were cut into $80 \mu \mathrm{m}$ coronal sections with a vibrating microtome (VT 1000S; Leica). Sections were cryoprotected with $30 \%$ sucrose and frozen/thawed three times with liquid nitrogen to enhance antibody penetration. Sections were then incubated in primary
Table 2. Statistical analysis of synaptic markers in newborn granule cells

\begin{tabular}{llccc}
\hline & Two-way ANOVA & $p_{\text {genotype }}$ & $p_{\text {time }}$ & Interaction \\
\hline $\begin{array}{l}\alpha 2 \text {-Subunit } \\
\text { Apical dendrite }\end{array}$ & $F_{(3,16)}=7.207$ & 0.014 & 0.170 & 0.003 \\
$\quad \begin{array}{l}\text { Cell body } \\
\text { Gephyrin }\end{array}$ & $F_{(3,16)}=8.617$ & $<0.0001$ & 0.071 & 0.001 \\
$\quad$ & & & & \\
$\quad$ Apical dendrite & $F_{(3,16)}=6.703$ & 0.001 & 0.849 & 0.004 \\
$\quad$ Cell body & $F_{(3,16)}=6.622$ & $<0.0001$ & 0.009 & 0.004 \\
$\begin{array}{l}\text { GAD65 } \\
\quad \text { Apical dendrite }\end{array}$ & $F_{(3,16)}=1.561$ & 0.525 & $<0.0001$ & 0.238 \\
$\quad$ Cell body & $F_{(3,16)}=0.352$ & 0.292 & 0.348 & 0.788 \\
\hline
\end{tabular}

The density of $\alpha 2$-subunit and gephyrin clusters, representing putative postsynaptic sites, as well as GAD65 ${ }^{+}$ puncta, representing presynaptic terminals, was analyzed in WT and $\alpha 2$-FL mice. For each genotype, data were further analyzed by one-way ANOVA, followed by Dunn's post hoc test (see Results).
A
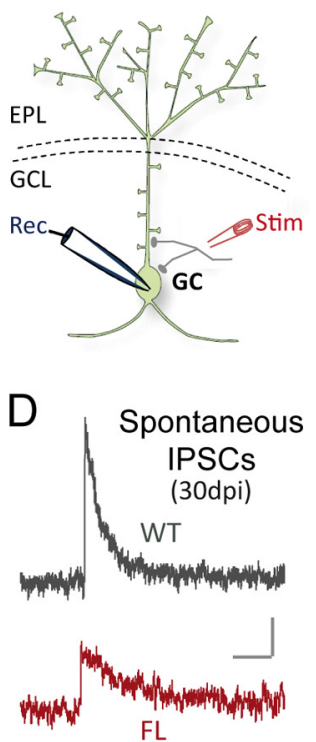

$\mathrm{F}$

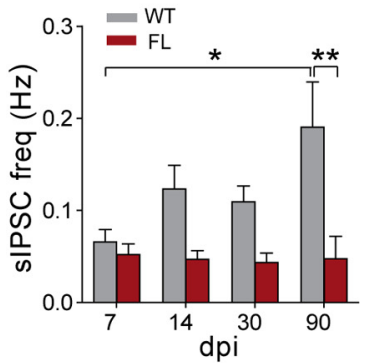

B

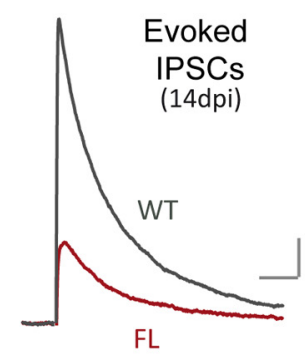

scaled

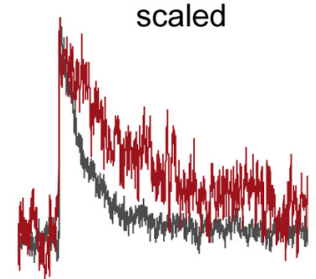

G

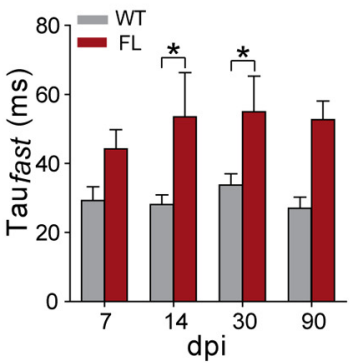

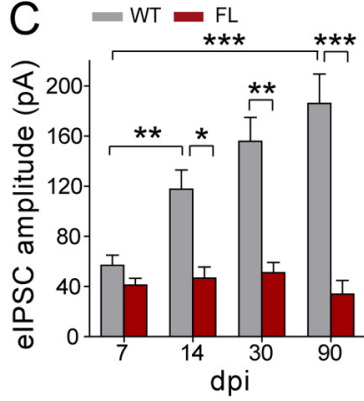

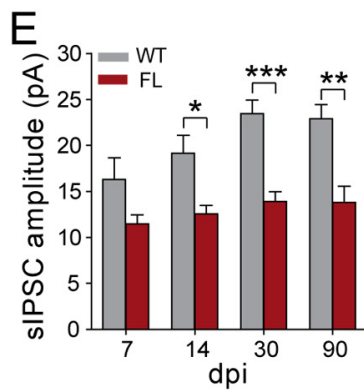

$\mathrm{H}$

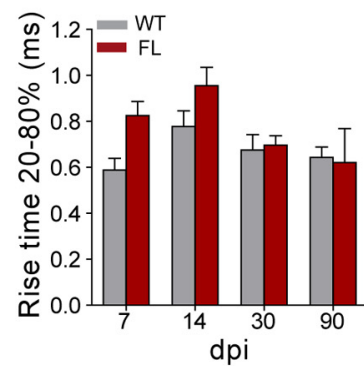

Figure 2. Reduction of GABAergic currents in newborn $\mathrm{GCS}$ from $\alpha 2$-FL mice. Electrophysiological properties of eGFP ${ }^{+} \mathrm{GCS}$ were assessed by whole-cell patch-clamp recordings. $\boldsymbol{A}$, Recording configuration. Rec, Recording electrode; Stim, stimulation electrode located in the GCL to elicit IPSCs (glass pipette). $\boldsymbol{B}$, Examples of elPSCs recorded at $V_{\mathrm{c}}=0 \mathrm{mV}$ at 14 dpi. Representative traces were averaged from $>20$ recorded IPSCs. Calibration: 20 ms, 25 pA. C, Histograms of elPSC amplitude (picoamperes; mean \pm SD) for WT and $\alpha 2$-FL cells. $D$, Examples of sIPSCs recorded from a WT cell (gray) and an $\alpha 2$-FL cell (red) at $30 \mathrm{dpi}\left(V_{c}=\right.$ $0 \mathrm{mV}$; calibration: $50 \mathrm{~ms}, 10 \mathrm{pA}$ ). In the right, normalized sIPSC amplitudes are displayed to illustrate their relative kinetics. $\boldsymbol{E}, \boldsymbol{F}$, Histograms of the frequency and amplitude of sIPSCs in WT and $\alpha 2$-FL cells (mean \pm SD). $\mathbf{G}, \boldsymbol{H}$, Histograms of sIPSC decay time constant ( $\operatorname{Tau}_{\text {fast }}$ derived from double-exponential fitting) and rise time (measured from 20 to $80 \%$ of peak amplitude). For statistical analysis, see Tables 3 and $4 A\left({ }^{*} p<0.05 ;{ }^{* *} p<0.01 ;{ }^{* * *} p<0.001\right)$.

antibodies against gephyrin and GFP (Table 1) diluted in Tris-buffered saline containing $10 \%$ normal goat serum for $72 \mathrm{~h}$ at $4^{\circ} \mathrm{C}$. After several rinses, the sections were incubated with rabbit IgGs coupled to biotin (1:250; Vector Laboratories) and mouse IgGs coupled to $1.4 \mathrm{~nm}$ colloidal gold particles (1:200; Nanoprobes) for $24 \mathrm{~h}$ at room temperature. A standard immunoperoxidase reaction was performed to detect eGFP 
(Vectastain Elite; Vector Laboratories), whereas nanogold particles were visualized with the gold enhanced-EM formulation (Nanoprobes), as described by the manufacturer. The sections were treated with $0.5 \%$ $\mathrm{OsO}_{4}$ and $1 \%$ uranyl acetate, dehydrated, and embedded into Epon 812 . Serial ultrathin sections were collected on copper single-hole grids and observed in a JEM-1010 transmission electron microscope (Jeol) equipped with a side-mounted CCD camera (Mega View III; Soft Imaging System) for photography.

\section{Electrophysiology}

For patch-clamp recordings, $\alpha 2$-FL and WT mice were deeply anesthetized with isoflurane (Mundipharma) and swiftly decapitated. The OB and frontal cortices were rapidly dissected and placed in ice-cold ACSF containing the following (in $\mathrm{mm}$ ): $124 \mathrm{NaCl}, 3 \mathrm{KCl}, 1.3 \mathrm{MgSO}_{4}, 26$ $\mathrm{NaHCO}_{3}, 1.25 \mathrm{NaHPO}_{4}, 20$ glucose, and $2 \mathrm{CaCl}(\sim 310$ mOsm, pH 7.3 when bubbled with a mixture of $95 \% \mathrm{O}_{2}$ and $5 \% \mathrm{CO}_{2}$; all chemicals from Sigma). They were then glued to a block of $4 \%$ agarose and placed, submerged in ice-cold ACSF, in the cutting chamber of a vibrating microtome (VT 1200S; Leica). Horizontal slices (300 $\mu \mathrm{m}$ thick) of the OBs were placed in bubbled ACSF in a warming bath at $35^{\circ} \mathrm{C}$ for $30 \mathrm{~min}$ and then at room temperature (i.e., $22 \pm 1^{\circ} \mathrm{C}$ ). For whole-cell recordings, individual slices were placed in a chamber mounted on a Carl Zeiss Axioskop upright microscope and continuously perfused $(1.5 \mathrm{ml} / \mathrm{min})$ with room temperature bubbled ACSF. Slices were visualized using a $40 \times$ water-immersion objective, a halogen light source, differential interference contrast filters (Carl Zeiss), and a CCD camera (C7500; Hamamatsu). We obtained whole-cell patch-clamp recordings from visually targeted eGFP-labeled GCs. Patch pipettes, pulled from borosilicate glass [1.5 mm outer diameter, $1.17 \mathrm{~mm}$ inner diameter (Harvard Apparatus); P-87 Flaming/Brown micropipette puller (Sutter Instrument)], had resistances of 6-10 $\mathrm{M} \Omega$, and were filled with a cesium gluconate-based solution [in mm: $126 \mathrm{Cs}$-gluconate, $6 \mathrm{CsCl}, 2 \mathrm{NaCl}, 10$ Na-HEPES, 10 D-glucose, 0.2 Cs-EGTA, 0.3 GTP, 2 Mg-ATP, and 0.2 cAMP (with $0.15 \%$ biocytin; 280-290 mOsm, pH 7.3)]. Rhodamine $(0.1-0.4 \%)$ was included in the internal solution for $\mathrm{eGFP}^{+}$cell recordings. All membrane potentials indicated in the text are corrected for a measured liquid junction potential of $+10 \mathrm{mV}$.

Adult-born cells were identified by either double labeling with both eGFP and rhodamine during recording or the presence of eGFP in the tip of the patch pipette after membrane rupture. eGFP-targeted recordings that did not meet either of these criteria were discarded from our analyses. Recordings were obtained via an Axopatch 1D amplifier. Signals were Bessel filtered at $2 \mathrm{kHz}$, digitized, and sampled at intervals of $20-450 \mu \mathrm{s}$ $(2.2-50 \mathrm{kHz})$ according to the individual protocols. Compensation for fast capacitance in cell-attached mode was $\sim 80 \%(12-13 \mathrm{pF}, 3-5 \mu \mathrm{s})$; we also compensated for membrane capacitance $\left(C_{\mathrm{m}}\right)$ but not series resistance $\left(R_{\mathrm{s}}\right)$, after membrane rupture. With $C_{\mathrm{m}}$ compensation inactivated, values of $C_{\mathrm{m}}, R_{\mathrm{s}}$ and membrane resistance $\left(R_{\mathrm{m}}\right)$ were estimated using peak and steady-state currents, respectively, observed in response to a 5 $\mathrm{mV}$ membrane step. Any experiment in which $R_{\mathrm{s}}$ changed by $>20 \%$ was discarded from our analyses. Currents mediated by $\mathrm{Na}^{+}$voltage-gated channels were measured under voltage-clamp conditions. Depolarizing pulses (100 ms) from $-70 \mathrm{mV}$ to incremental steps $(5 \mathrm{mV})$, up to +10 $\mathrm{mV}$, were given at a rate of $1 \mathrm{~Hz} . \mathrm{Na}^{+}$currents were measured after subtraction of scaled passive current responses to the appropriate voltage steps.

Synaptic responses were evoked using a small monopolar stimulating glass pipette (3-4 $\mu \mathrm{m}$ tip diameter, pulled from $1.5 \mathrm{~mm}$ outer diameter and $1.17 \mathrm{~mm}$ inner diameter borosilicate glass, and filled with ACSF), finely positioned in the GC layer (GCL). Spontaneous (s) and evoked (e) synaptic currents were analyzed with Elphy software (Gerard Sadoc, Gifsur-Yvette, France). The amplitude of ePSCs was measured from averaged traces (10-30 traces). Spontaneous synaptic currents were recorded during $\geq 5$ min. Rise times were measured between 20 and $80 \%$ of peak amplitude. For IPSCs, decay time constants were derived by fitting the formula $F(t)=a \times \exp \left(-t / t_{\text {fast }}\right)+b \times \exp \left(-t / t_{\text {slow }}\right)$, where $a$ and $b$ are the peak amplitude of fast and slow components, respectively, and $t_{\text {fast }}$ and $t_{\text {slow }}$ are the respective decay time constants. A monoexponential fitted all EPSCs.
Table 3. Statistical analysis of postsynaptic currents

\begin{tabular}{llccl}
\hline & Two-way ANOVA & $p_{\text {genotype }}$ & $p_{\text {time }}$ & Interaction \\
\hline elPSC amplitude & $F_{(3,99)}=8.569$ & $<0.0001$ & $<0.0001$ & 0.0001 \\
sIPSC amplitude & $F_{(3,75)}=0.876$ & $<0.0001$ & 0.017 & 0.458 \\
sIPSC frequency & $F_{(3,85)}=2.105$ & 0.001 & 0.014 & 0.105 \\
sIPSC decay time & $F_{(3,63)}=0.243$ & $<0.0001$ & 0.691 & 0.866 \\
sIPSC rise time & $F_{(3,64)}=1.363$ & 0.049 & 0.011 & 0.262 \\
sEPSC amplitude & $F_{(3,98)}=0.301$ & 0.595 & 0.348 & 0.823 \\
sEPSC frequency & $F_{(3,95)}=0.981$ & 0.006 & 0.006 & 0.405 \\
sEPSC decay time & $F_{(3,99)}=1.199$ & 0.772 & 0.728 & 0.314 \\
sEPSC rise time & $F_{(3,108)}=0.683$ & 0.703 & 0.04 & 0.564 \\
Capacitance & $F_{(3,126)}=0.815$ & 0.484 & 0.0011 & 0.488 \\
Membrane resistance & $F_{(3,115)}=1.12$ & 0.052 & $<0.0001$ & 0.3442 \\
Na ${ }^{+}$current density & $F_{(3,122)}=0.579$ & 0.4143 & $<0.0001$ & 0.630 \\
\hline
\end{tabular}

Additional analysis per genotype and/or time point is presented in Table 4 .

\section{Statistical analyses}

Data are presented as mean \pm SD or SEM (see Tables 2-6). Statistical analyses include one-way and two-way ANOVA with post hoc correction using Prism5 software (GraphPad Software). For a given day postinjection, $\alpha 2$-FL and WT groups were compared two-by-two by Student's $t$ test and Mann-Whitney $U$ test.

\section{Results}

\section{Conditional deletion of Gabra2 causes delayed removal of $\alpha 2-\mathrm{GABA}_{\mathrm{A}}$ Rs in adult-born GCs}

GABAergic inhibition in GCs is mediated mainly by $\alpha 2$ containing $\mathrm{GABA}_{\mathrm{A}} \mathrm{Rs}$ (Panzanelli et al., 2009). To investigate the functional impact of GABAergic inputs in adult-born GCs, we silenced GABAergic transmission by injecting a Cre-eGFPencoding lentivirus into the RMS of adult $\alpha 2$-FL mice (Fig. $1 A, B)$. Cre recombinase inactivates Gabra2 by inducing a sitespecific recombination of exon 5 flanked by LoxP sites (Panzanelli et al., 2011), whereas eGFP allows the visualization of transduced cells. Immunohistochemistry revealed the presence of Cre recombinase in the nucleus of $\mathrm{eGFP}^{+}$cells from 7 to $90 \mathrm{dpi}$ (data not shown).

We performed double labeling for eGFP and the $\alpha 2$-subunit to verify the efficacy and time course of Cre-mediated deletion of Gabra2. Quantification was done in both the cell body and the proximal domain (i.e., the initial portion of the apical dendrite located in the GCL and extending up to $50 \mu \mathrm{m}$ away from the cell body) of the apical dendrite (Fig. $1 C-E$ ). Two-way ANOVA revealed a significant effect of genotype and a significant interaction between time and genotype in both regions (Table 2). In WT mice, the density of $\alpha 2$-subunit-positive perisomatic clusters increased significantly from 7 to $90 \mathrm{dpi}$, whereas that of dendritic clusters remained constant during the same period (one-way ANOVA; cell body, $F_{(3,8)}=5.752, p=0.0214$; apical dendrite, $\left.F_{(3,8)}=3.438, p=0.07\right)$. Surprisingly, in $\alpha 2$-FL mice, $\alpha 2$ subunit-positive clusters were still detectable on $\mathrm{eGFP}^{+}$cells at 7 and 14 dpi. However, a strong decrease was observed at 30 and 90 dpi in both the somatic and dendritic compartments (Fig. 1E; one-way ANOVA; cell body, $F_{(3,8)}=5.677, p=0.022$; apical dendrite, $\left.F_{(3,8)}=7.879, p=0.009\right)$. These results suggest that Gabra2 is expressed early in adult-born GCs and that, after Cremediated inactivation, the loss of $\alpha 2$-subunit is a protracted process that becomes detectable after $14 \mathrm{dpi}$.

We next verified whether the $\alpha 3$ subunit, which is also expressed in GCs (Fritschy and Mohler, 1995), is upregulated after Gabra2 inactivation (Fig. $1 D, F$ ). At 90 dpi, there was no difference in $\alpha 3$-subunit cluster density in GCs of $\alpha 2$-FL and WT mice (cell body, $t_{(3)}=1.147, p=0.315$; apical dendrite, $t_{(3)}=0.284$, $p=0.790)$, suggesting that deletion of the $\alpha 2$-subunit is not 
Table 4. Properties of postsynaptic currents

\begin{tabular}{|c|c|c|c|c|c|c|}
\hline & dpi & WT & $\alpha 2-\mathrm{FL}$ & $t$ test & MW test & Dunn's test \\
\hline \multicolumn{7}{|l|}{$A$, IPSCS } \\
\hline \multirow[t]{4}{*}{ eIPSC amplitude (pA) } & 7 & $56.86 \pm 8.21 n=11$ & $41.15 \pm 5.32 n=13$ & 0.113 & 0.132 & NS \\
\hline & 14 & $111.80 \pm 15.24 n=15$ & $46.60 \pm 9.01 \mathrm{~N}=12$ & 0.002 & 0.0059 & $* *$ \\
\hline & 30 & $155.70 \pm 19.20 n=12$ & $51.04 \pm 8.05 n=18$ & $* * *$ & $* * *$ & $* * *$ \\
\hline & 90 & $186.01 \pm 23.32 n=13$ & $33.78 \pm 11.09 n=13$ & $* * *$ & $* * *$ & $* * *$ \\
\hline \multirow[t]{2}{*}{ One-way ANOVA } & & $p=0.0002$ & $p=0.1627$ & & & \\
\hline & & 7 versus $14^{* *} ; 7$ versus $90^{* * *}$ & & & & \\
\hline \multirow[t]{4}{*}{ sIPSC frequency $(\mathrm{Hz})$} & 7 & $0.06 \pm 0.01 n=9$ & $0.05 \pm 0.01 n=12$ & 0.452 & 0.546 & NS \\
\hline & 14 & $0.12 \pm 0.03 n=11$ & $0.05 \pm 0.01 n=7$ & 0.037 & 0.0774 & NS \\
\hline & 30 & $0.10 \pm 0.02 n=15$ & $0.04 \pm 0.01 n=17$ & 0.0041 & 0.0034 & NS \\
\hline & 90 & $0.24 \pm 0.07 n=15$ & $0.05 \pm 0.02 n=7$ & 0.068 & 0.0048 & $* *$ \\
\hline \multirow[t]{2}{*}{ One-way ANOVA } & & $p=0.031$ & $p=0.1627$ & & & \\
\hline & & 7 versus $90^{*}$ & & & & \\
\hline \multirow[t]{4}{*}{ sIPSC amplitude (pA) } & 7 & $16.30 \pm 2.34 n=9$ & $11.48 \pm 0.98 n=8$ & 0.09 & 0.074 & NS \\
\hline & 14 & $19.17 \pm 1.94 n=12$ & $12.57 \pm 0.90 n=9$ & 0.0124 & 0.0062 & $*$ \\
\hline & 30 & $23.46 \pm 1.48 n=14$ & $13.93 \pm 1.04 n=13$ & $* * *$ & $* * *$ & $* * *$ \\
\hline & 90 & $22.90 \pm 1.54 n=13$ & $13.81 \pm 1.76 n=5$ & 0.0043 & 0.0078 & $* *$ \\
\hline One-way ANOVA & & $p=0.220$ & $p=0.537$ & & & \\
\hline \multirow[t]{4}{*}{ sIPSC decay time constant (ms) } & 7 & $29.29 \pm 3.97 n=7$ & $44.27 \pm 5.53 n=6$ & 0.0463 & 0.0734 & NS \\
\hline & 14 & $28.15 \pm 2.73 n=12$ & $53.49 \pm 12.90 n=7$ & 0.0249 & 0.09 & $*$ \\
\hline & 30 & $33.73 \pm 3.30 n=14$ & $54.98 \pm 10.33 n=9$ & 0.0305 & 0.0298 & * \\
\hline & 90 & $27.02 \pm 3.242 n=13$ & $52.67 \pm 5.47 n=3$ & 0.0035 & 0.0222 & NS \\
\hline One-way ANOVA & & $p=0.438$ & $p=0.889$ & & & \\
\hline \multirow[t]{4}{*}{ sIPSC rise time $20-80 \%$ (ms) } & 7 & $0.59 \pm 0.05 n=7$ & $0.82 \pm 0.06 n=6$ & 0.012 & 0.008 & NS \\
\hline & 14 & $0.78 \pm 0.07 n=12$ & $0.95 \pm 0.08 n=7$ & 0.119 & 0.139 & NS \\
\hline & 30 & $0.68 \pm 0.07 n=14$ & $0.70 \pm 0.04 n=9$ & 0.815 & 0.378 & NS \\
\hline & 90 & $0.64 \pm 0.04 n=13$ & $0.62 \pm 0.15 n=4$ & 0.841 & 0.533 & NS \\
\hline One-way ANOVA & & $p=0.28$ & $p=0.0263$ & & & \\
\hline \multicolumn{7}{|l|}{ B, EPSCS } \\
\hline \multirow[t]{4}{*}{ SEPSC frequency $(\mathrm{Hz})$} & 7 & $1.14 \pm 0.74 n=11$ & $1.12 \pm 0.27 n=11$ & 0.653 & 0.5546 & NS \\
\hline & 14 & $4.43 \pm 0.82 n=12$ & $1.78 \pm 0.58 n=11$ & 0.0175 & 0.0151 & $*$ \\
\hline & 30 & $5.42 \pm 0.94 n=12$ & $3.13 \pm 0.52 n=19$ & $0.028^{*}$ & 0.0744 & * \\
\hline & 90 & $3.87 \pm 0.68 n=11$ & $2.21 \pm 0.67 n=16$ & 0.1051 & 0.0543 & NS \\
\hline \multirow[t]{2}{*}{ One-way ANOVA } & & $p=0.021$ & $p=0.126$ & & & \\
\hline & & 7 versus $14^{*} ; 7$ versus $30^{* *}$ & & & & \\
\hline \multirow[t]{4}{*}{ sEPSC amplitude (pA) } & 7 & $8.88 \pm 0.91 n=11$ & $8.35 \pm 1.10 n=11$ & 0.7147 & 0.4307 & NS \\
\hline & 14 & $9.31 \pm 1.36 n=12$ & $9.37 \pm 0.62 n=13$ & 0.968 & 0.849 & NS \\
\hline & 30 & $8.64 \pm 0.84 n=14$ & $9.38 \pm 0.88 n=19$ & 0.5561 & 0.392 & NS \\
\hline & 90 & $7.26 \pm 0.37 n=12$ & $8.33 \pm 0.65 n=14$ & 0.1819 & 0.2077 & NS \\
\hline One-way ANOVA & & $p=0.583$ & $p=0.251$ & & & \\
\hline \multirow{4}{*}{ sEPSC decay time constant (ms) } & 7 & $7.58 \pm 1.57 n=11$ & $9.57 \pm 1.31 n=10$ & 0.3471 & 0.1698 & NS \\
\hline & 14 & $9.61 \pm 1.76 n=13$ & $8.69 \pm 1.63 n=13$ & 0.7036 & 0.7976 & NS \\
\hline & 30 & $9.46 \pm 1.37 n=14$ & $10.79 \pm 1.65 n=19$ & 0.5586 & 0.8698 & NS \\
\hline & 90 & $12.16 \pm 2.41 n=11$ & $8.36 \pm 1.25 n=16$ & 0.1414 & 0.1671 & NS \\
\hline One-way ANOVA & & $p=0.2673$ & $p=0.718$ & & & \\
\hline \multirow{4}{*}{ sEPSC rise time $20-80 \%$ (ms) } & 7 & $1.03 \pm 0.05 n=11$ & $0.98 \pm 0.06 n=15$ & 0.5043 & 0.6037 & NS \\
\hline & 14 & $0.90 \pm 0.05 n=13$ & $0.82 \pm 0.042 n=16$ & 0.2173 & 0.3131 & NS \\
\hline & 30 & $0.83 \pm 0.06 n=14$ & $0.78 \pm 0.06 n=19$ & 0.5617 & 0.6229 & NS \\
\hline & 90 & $0.87 \pm 0.04 n=12$ & $0.98 \pm 0.13 n=16$ & 0.506 & 0.9815 & NS \\
\hline One-way ANOVA & & $p=0.0775$ & $p=0.1314$ & & & \\
\hline
\end{tabular}

Values are mean \pm SEM. General statistics are presented in Table 3. Each genotype was analyzed by one-way ANOVA, followed by Dunn's posthoctest (NS, $\left.p>0.05 ;{ }^{*} p<0.05 ;{ }^{* *} p<0.01 ;{ }^{* * *} p<0.001\right)$. WT and FL groups were compared two-by-two by Student's $t$ test and Mann-Whitney $U$ test (MW).

compensated by increased expression of the $\alpha 3$-subunit. We then analyzed how deletion of the $\alpha 2$-subunit affects GABAergic innervation of GCs. We first quantified postsynaptic gephyrin clusters (Fig. $1 G, H$ ) and found a significant decrease in GCs of $\alpha 2-\mathrm{FL}$ mice, in parallel with the depletion of the $\alpha 2$-subunit (one-way ANOVA; cell body, $F_{(3,8)}=6.735, p=0.014$; apical dendrite, $F_{(3,8)}=7.472, p=0.01$; for complete statistics, see Table 2). In contrast, there was no difference, at any time point, in the number of $\mathrm{GAD} 5^{+}$terminals impinging onto the cell body and the apical dendrite of $\mathrm{eGFP}^{+}$GCs (Fig. 1I,J; Table 2). These data indicate that GABAergic innervation of new GCs is maintained after deletion of the $\alpha 2$-subunit despite the disruption of the postsynaptic gephyrin scaffold.

\section{Conditional deletion of Gabra2 causes delayed decrease of GABAergic currents in adult-born GCs}

To investigate the functional consequence of Gabra2 inactivation, we performed whole-cell patch-clamp recordings on acute slices. Using a focal electrical stimulation delivered in the GCL (Fig. 2A), we recorded eIPSCs in adult-born GCs (Fig. 2B). Twoway ANOVA revealed a significant effect of time and genotype and a significant interaction between these factors (for values and 
Table 5. Intrinsic membrane properties of newborn granule cells

\begin{tabular}{|c|c|c|c|c|c|c|}
\hline & dpi & WT & $\alpha 2-\mathrm{FL}$ & $t$ test & MW test & Dunn's test \\
\hline \multirow[t]{4}{*}{$C_{m}(p F)$} & 7 & $12.09 \pm 1.42 n=13$ & $11.40 \pm 0.89 n=16$ & 0.6727 & 0.8608 & NS \\
\hline & 14 & $13.70 \pm 0.86 n=17$ & $12.49 \pm 0.80 n=16$ & 0.3148 & 0.3219 & NS \\
\hline & 30 & $10.70 \pm 0.74 n=17$ & $11.86 \pm 0.85 n=19$ & 0.3188 & 0.2347 & NS \\
\hline & 90 & $10.07 \pm 0.91 n=15$ & $9.07 \pm 0.61 n=21$ & 0.3487 & 0.4703 & NS \\
\hline One-way ANOVA & & $p=0.06$ & $\begin{array}{l}p=0.0099 \\
14 \text { versus } 90^{*}\end{array}$ & & & \\
\hline \multirow[t]{4}{*}{$R_{\mathrm{m}}(\mathrm{G} \Omega)$} & 7 & $1.37 \pm 0.14 n=13$ & $1.80 \pm 0.28 n=14$ & 0.1992 & 0.6979 & NS \\
\hline & 14 & $0.79 \pm 0.09 n=16$ & $0.76 \pm 0.071 n=16$ & 0.8536 & 0.8358 & NS \\
\hline & 30 & $0.73 \pm 0.10 n=16$ & $0.80 \pm 0.12 n=17$ & 0.6823 & 0.8712 & NS \\
\hline & 90 & $0.67 \pm 0.08 n=14$ & $0.90 \pm 0.10 n=16$ & 0.0775 & 0.0504 & NS \\
\hline \multirow[t]{2}{*}{ One-way ANOVA } & & $p=0.006$ & $p=0.0026$ & & & \\
\hline & & 7 versus $14^{*} ; 7$ versus $30^{* *} ; 7$ versus $90^{* *}$ & 7 versus $14^{* *} ; 7$ versus $30^{* *}$ & & & \\
\hline \multirow[t]{4}{*}{$\mathrm{iNa}^{+}(\mathrm{pA} / \mathrm{pF})$} & 7 & $87.08 \pm 18.49 n=12$ & $93.68 \pm 13.96 n=16$ & 0.7734 & 0.6260 & NS \\
\hline & 14 & $141.0 \pm 14.32 n=17$ & $146.1 \pm 12.47 n=16$ & 0.7893 & 0.6787 & NS \\
\hline & 30 & $179.2 \pm 15.36 n=17$ & $168.4 \pm 18.59 n=19$ & 0.6610 & 0.4661 & NS \\
\hline & 90 & $174.6 \pm 21.65 n=11$ & $158.5 \pm 22.92 n=17$ & 0.6338 & 0.5409 & NS \\
\hline \multirow[t]{2}{*}{ One-way ANOVA } & & $p=0.0036$ & $p=0.0192$ & & & \\
\hline & & 7 versus $30^{* *} ; 7$ versus $90^{*}$ & 7 versus $30^{*}$ & & & \\
\hline
\end{tabular}

$C_{\mathrm{m}}$, Membrane capacitance; $R_{\mathrm{m}}$, membrane resistance; $\mathrm{iNa}^{+}$, density of voltage-dependant $\mathrm{Na}{ }^{+}$channels-mediated currents (normalized to $C_{\mathrm{m}}$ ). Values are mean $\pm \mathrm{SEM}$. General statistics are presented in Table 3 . Each genotype was analyzed by one-way ANOVA, followed by Dunn's post hoc test (NS, $p>0.05 ;{ }^{*} p<0.05 ;{ }^{* *} p<0.01$; ${ }^{* * *} p<0.001$ ). For a given time point, WT and $\alpha 2$-FL groups were compared two-by-two by Student's t test and Mann-Whitney U test (MW).

statistics, see Tables 3, 4A). In cells recorded from WT mice, we observed a significant increase in the amplitude of eIPSCs from 7 to 90 dpi (one-way ANOVA, $p=0.002$ ), consistent with the progressive increase in $\alpha 2$-subunit and gephyrin clusters described above. However, the amplitude of eIPSCs remained constant in $\alpha 2$-FL mice, leading to a fivefold difference at $90 \mathrm{dpi}$ when compared with WT (Fig. 2C; Table 4A). We next tested the consequences of ablation of the $\alpha 2$-subunit on the physiological properties of sIPSCs (Fig. 2D-H; Table 4A). Although there was no change over time in either genotype (two-way ANOVA; Table 3 ), the sIPSC amplitudes were significantly lower in $\alpha 2$-FL cells than in WT at all time points after 14 dpi (Fig. 2E; Table 4A). Concomitantly, the sIPSC frequency increased over time in WT cells but not in mutant GCs (one-way ANOVA, $p=0.031$ ), reflecting the progressive increase in the number of functional synapses during unperturbed neuronal maturation (Fig. $2 F$ ). The decay time constants were longer in mutant cells (Fig. $2 D, G$ ), but the rise times remained unchanged (Fig. $2 H$; Tables 3, 4A). In contrast to these changes, we found no genotype effect on the membrane capacitance, input membrane resistance, and the $\mathrm{Na}^{+}$current density (Table 5). Thus, ablation of the $\alpha 2$-subunit led to a marked reduction in the functional properties of GABAergic synapses without changing the intrinsic membrane properties of newborn GCs. Collectively, these results are consistent with the immunohistochemical data showing an increased number of GABAergic synapses during the morphological maturation of GCs, a process that is dramatically altered in mutant cells. Inactivation of Gabra2 leads to the formation of adult-born GCs receiving fewer GABAergic inputs characterized by low amplitude and slow decay time constants. These alterations appear at $\sim 14 \mathrm{dpi}$ and become even more apparent at later time points.

\section{GC dendritic morphology is affected after Gabra2 inactivation}

To determine whether the reduced afferent GABAergic signaling caused by conditional deletion of Gabra2 has an influence on the survival of newborn GCs, we measured the density of eGFP ${ }^{+}$cells at different time points after viral injection. We found that cell density did not differ between the two genotypes (i.e., at 90 dpi $\mathrm{WT}, 1350 \pm 50$ cells $/ \mathrm{mm}^{2} ; \alpha 2$-FL, $1200 \pm 27$ cells $/ \mathrm{mm}^{2}$; unpaired $t$ test, $p=0.676$ ), indicating that deletion of the $\alpha 2$ - subunit does not affect GC survival. Moreover, the fraction of deep versus superficial GCs is not affected in $\alpha 2$-FL mice, as tested at 30 and 90 dpi (data not shown). However, double labeling for eGFP and doublecortin revealed that mutant GCs have a prolonged expression of doublecortin compared with control cells (30 dpi, $7.1 \pm 0.9$ and $19 \pm 1.8 \%$ in WT and $\alpha 2$-FL mice, respectively; $n=688$ and 394 cells; 90 dpi, $5 \pm 0.1$ and $11.1 \pm$ $0.7 \%$ in WT and $\alpha 2$-FL mice; $n=710$ and 564 cells). These results indicate that adult-born GCs lacking $\alpha 2-\mathrm{GABA}_{\mathrm{A}}$ Rs exhibit impaired structural maturation compared with WT counterparts.

We next asked whether the reduction in GABAergic inputs alters the dendritic arborization of newborn GCs. As expected for maturing cells, Sholl analysis of WT control cells revealed a progressive development of the dendritic tree, in particular in the distal portion starting $\sim 100 \mu \mathrm{m}$ away from the cell body (Fig. $3 A$ ). Calculating the total AUC (Fig. 3A), we observed a $44 \%$ increase between 7 and $30 \mathrm{dpi}$, followed by a significant reduction at $90 \mathrm{dpi}$ (one-way ANOVA, $F_{(3,8)}=30.07, p=0.0001$ ). This biphasic evolution suggests that the apical dendrite undergoes a prominent remodeling after an initial period of exuberant growth. In $\alpha 2$-FL mice, dendritic development beyond $14 \mathrm{dpi}$ was altered compared with WT (Fig. 3B). The Sholl analysis revealed a slow increase of the AUC between 14 and $90 \mathrm{dpi}$, which reached significance only at later time points (Table 6). Likewise, analysis of the total dendritic length and the number of terminal branches revealed significant effects of genotype and time, as well as a strong interaction between both factors (two-way ANOVA; Table 7). Although these parameters increased significantly at 30 and 90 dpi in WT cells, there were only limited changes in GCs from $\alpha 2$-FL cells (Fig. 3C-E). Therefore, the dendritic growth of adult-born GCs is severely impaired during ablation of $\alpha 2-\mathrm{GABA}_{\mathrm{A}} \mathrm{Rs}$.

\section{Gabra2 inactivation causes rearrangements of glutamatergic synapses}

To further describe how $\alpha 2-\mathrm{GABA}_{\mathrm{A}}$ Rs modulate GC differentiation and synaptic integration, we investigated whether excitatory synapses also change after Gabra2 inactivation. Quantification of spine density in the GCL and EPL (Fig. 4A-D) revealed highly significant effects of time and genotype, as well as a strong interaction between these factors (two-way ANOVA; 
Table 7). In WT mice, spine density increased from 7 to $14 \mathrm{dpi}$, followed by a stabilization and decrease between 30 and 90 dpi (Fig. $4 B, D$ ). This transient peak in spine density is consistent with previous work (Whitman and Greer, 2007) and may be related to the critical window of activity-dependent plasticity that characterizes GC development (Kelsch et al., 2009; Nissant et al., 2009). A similar trend was seen in $\alpha 2$-FL mice, but the peak in spine density between 14 and 30 dpi was much less pronounced (Fig. $4 B, D$ ). Despite these changes in spine density, there were no obvious alterations in spine morphology, and spine neck length and head area were similar in $\alpha 2$-FL and WT mice (data not shown). These data indicate that the $\alpha 2$-subunit is necessary for exuberant spine growth, which are then pruned after 30 dpi.

We used antibodies against PSD95 to understand whether the lower spine density seen in mutant GCs is accompanied by a rearrangement of glutamatergic synapses (Fig. $4 E, F$ ). As seen at both 30 and 90 dpi, the number of PSD95 clusters located in spines was reduced in GCs of $\alpha 2$-FL mice, reflecting spine deficit (Fig. $4 E$; two-way ANOVA, $F_{(1,10)}=$ $1.028 ; p_{\text {genotype }}=0.005, p_{\text {time }}=0.334$, interaction $=0.582$ ). In contrast, the density of PSD95 clusters located on dendritic shafts was significantly higher in mutant GCs than in WT; the difference was seen at both time points, although a reduction of these clusters occurs with time (Fig. 4E; two-way ANOVA, $F_{(1,10)}=9.685 ; p_{\text {genotype }}=$ $0.007, p_{\text {time }}=0.011$, interaction $\left.=0.191\right)$. These observations suggest that deletion of $\alpha 2-\mathrm{GABA}_{\mathrm{A}} \mathrm{Rs}$ in GCs causes glutamatergic synapses to persist on dendritic shafts. To confirm this possibility, we performed preembedding immunoelectron microscopy for eGFP and gephyrin on $\alpha 2$-FL mice at $90 \mathrm{dpi}$. This analysis revealed that mitral/tufted cell dendrites establish reciprocal synapses with $\mathrm{eGFP}^{+}$profiles that lack the typical morphology of GC spines, supporting the idea that the reduction of spine density in mutant GCs is concurrent with the persistence of excitatory synapses on the dendritic shaft (Fig. 4G,H).

Finally, we analyzed the properties of glutamatergic synapses in mutated GCs. For this, sEPSCs were recorded during a $5 \mathrm{~min}$ baseline period. Analysis of their frequency revealed a similar profile as spine density, with significant effects of time and genotype (for values and statistics, see Tables 3, 4B). At 14 and $30 \mathrm{dpi}$, $\alpha 2$-FL cells had significantly fewer sEPSCs compared with WT GCs (one-way ANOVA, $p=0.021$; Fig. $4 I$, J), but their amplitude (one-way ANOVA, $p=0.583$; Fig. $4 K$ ), decay kinetics (one-way ANOVA, $p=0.267$; Fig. $4 L$ ), and rise time (one-way ANOVA, $p=0.08$; data not shown) remained unchanged. Thus, we con-
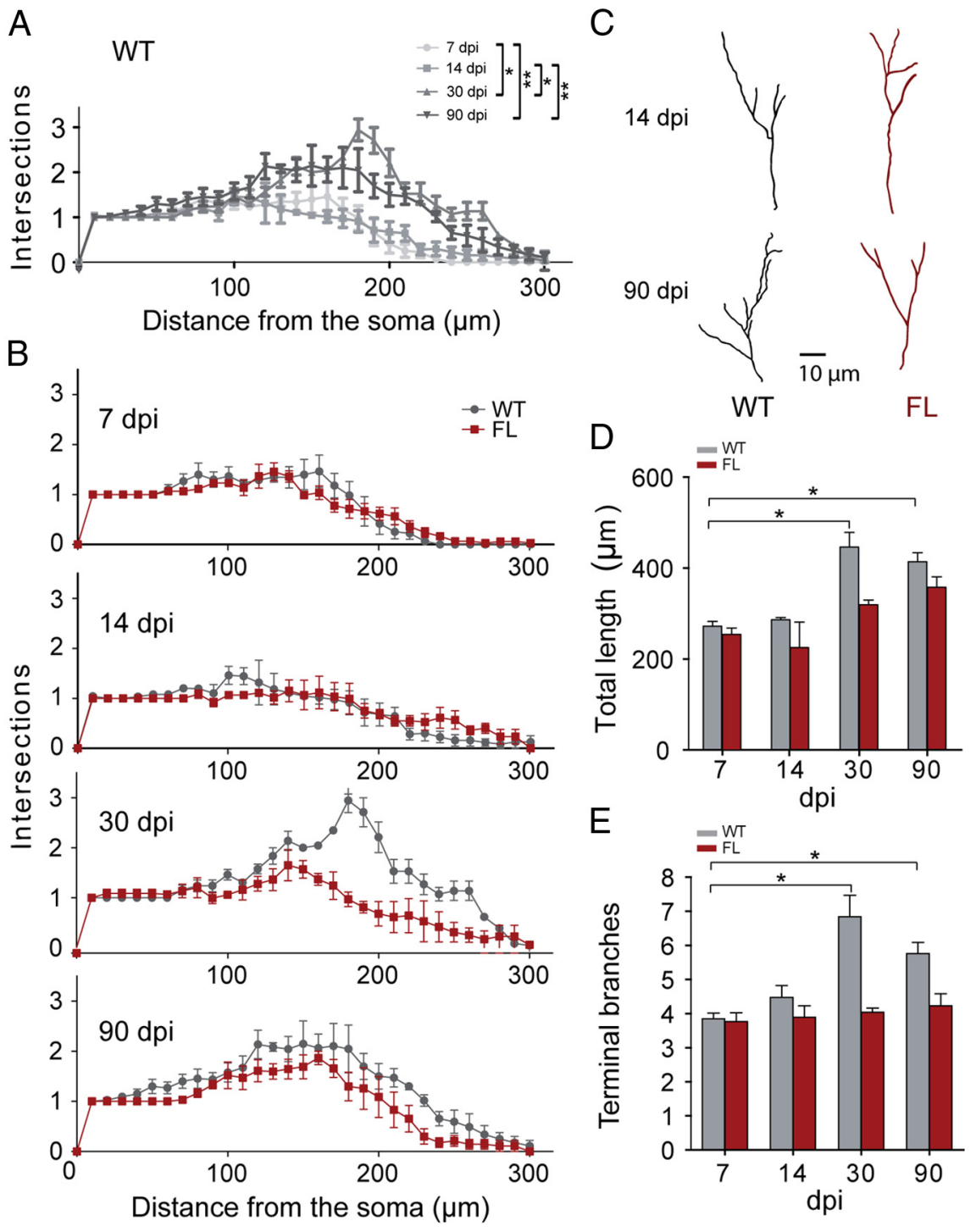

Figure 3. Morphometric analysis of apical dendrite arborization in newborn GCS of WT and $\alpha 2$-FL mice. A, Quantification by Sholl analysis of apical dendrites in eGFP ${ }^{+}$cells of WT mice. The number of intersections between eGFP ${ }^{+}$dendritic segments and virtual concentric lines centered on the soma and spaced by $10 \mu \mathrm{m}$ is displayed graphically. Each curve represents an individual one-way ANOVA with post hoc tests $\left({ }^{*} p<0.05,{ }^{* *} p<0.01,{ }^{* * *} p<0.001\right) . B$, Sholl analysis comparison between WT (gray line) $\alpha 2$-FL (red line) mice illustrating the reduction in dendritic complexity in newborn GCs from $\alpha 2$-FL mice. Most differences corresponding AUC was calculated in each graph (for mean values and statistical results, see Table 6). C, Representative drawings and number of terminal branches (mean \pm SEM) in WT and $\alpha 2$-FL mice (one-way ANOVA with post hoc tests; for statistical analysis, see Table 7; $\left.{ }^{*} p<0.05\right)$.

clude that GCs lacking $\alpha 2-\mathrm{GABA}_{\mathrm{A}}$ Rs develop fewer glutamatergic synapses but without changes to their function.

\section{Gabra2 inactivation in GCs occludes the effect of sensory deprivation on spine density}

We examined the putative role of $\alpha 2-\mathrm{GABA}_{\mathrm{A}} \mathrm{Rs}$ in activitydependent regulation of structural plasticity by challenging the sensory inputs to the OB circuit. We used both olfactory enrichment and dichlobenil-mediated sensory deprivation to study the adaptability of adult-born GCs to their novel neuronal environment. Mice were exposed to the enriched environment or injected with dichlobenil at $7 \mathrm{dpi}$ and were killed at 30 dpi (Fig. 5A). Two-way ANOVA analysis revealed significant 
Table 6. Statistical analysis of dendrite morphology: Scholl analysis

\begin{tabular}{cclll}
\hline & & AUC & & \\
\cline { 3 - 5 } Genotype & $N$ & Mean \pm SD & $t$ & \\
\hline $7 \mathrm{dpi}$ & 3 & $233 \pm 16$ & $t_{(4)}=0.412$ & NS \\
WT & 3 & $224 \pm 12$ & & \\
$\alpha 2$-FL & 3 & $237 \pm 19$ & $t_{(4)}=0.172$ & NS \\
$\begin{array}{c}14 \mathrm{dpi} \\
\text { WT }\end{array}$ & 3 & $240 \pm 7$ & & \\
$\alpha 2$-FL & 3 & $410 \pm 22$ & $t_{(4)}=3.748$ & 0.02 \\
$30 \mathrm{dpi}$ & 3 & & \\
WT & 3 & $262 \pm 32$ & & \\
$\alpha 2-\mathrm{FL}$ & 3 & $385 \pm 7$ & $t_{(4)}=6.954$ & 0.002 \\
$90 \mathrm{dpi}$ & 3 & $289 \pm 12$ & & \\
WT & 3 & & \\
$\alpha 2-\mathrm{FL}$ & 3 &
\end{tabular}

Pairwise comparison was performed by unpaired Student's $t$ test.

Table 7. Statistical analysis of dendrite morphology: dendrite topology and spine density

\begin{tabular}{llcrl}
\hline & Two-way ANOVA & $p_{\text {genotype }}$ & \multicolumn{1}{l}{$p_{\text {time }}$} & Interaction \\
\hline GCL spine density & $F_{(4,20)}=9.164$ & 0.000 & $<0.0001$ & 0.000 \\
EPL spine density & $F_{(3,16)}=5.542$ & $<0.0001$ & $<0.0001$ & 0.01 \\
Number of terminal branches & $F_{(3,16)}=5.887$ & 0.0001 & 0.0009 & 0.007 \\
Total dendritic tree length & $F_{(3,16)}=1.506$ & 0.003 & $<0.0001$ & 0.251
\end{tabular}

Differences in dendrite topology and spine densities were analyzed further by one-way ANOVA, followed by Dunn's post hoc test for each genotype (see Results).

effects of genotype $(p=0.001)$ and treatment $(p<0.0001)$, as well as a significant interaction $\left(F_{(2,12)}=6.38, p=0.013\right)$. In WT mice, odor enrichment caused a small increase in spine density that did not reach statistical significance, whereas olfactory deprivation caused a marked reduction in the density of spines $(p<0.001$; Fig. $5 B, C)$. In contrast, in $\alpha 2$-FL mice, neither enrichment nor sensory deafferentation caused significant changes in the density of spines. This indicates that inhibitory synaptic transmission mediated by $\alpha 2-\mathrm{GABA}_{\mathrm{A}} \mathrm{Rs}$ is required for structural adaptations of newborn GCs triggered by sensory enrichment or deprivation during the phase of dendritic/spine exuberance.

\section{Effects of early ablation of Gabra2 in progenitor neural cells} In the $\alpha 2$-FL model, deletion of the $\alpha 2$-subunit is complete only after GCs have reached the OB and started to establish synaptic connections within the preexisting network. We devised a complementary approach to inactivate Gabra2 in neural precursor cells of adult mice, before their final mitotic division and migration to the OB. This was achieved by crossing $\alpha 2$-FL mice with mice expressing an inducible form of Cre (Cre-ERT2) under the control of the GLAST promoter (Mori et al., 2006). At the age of 8 weeks, mice were treated systemically with Tam or Oil, and, 4 weeks later, they were injected stereotaxically with a lentiviral vector encoding eGFP (Fig. $6 A$ ). Adult-born GCs were investigated morphologically and functionally at 7 and $90 \mathrm{dpi}$.

Quantification of the number of $\mathrm{eGFP}^{+}$cells in the GCL showed no difference in mice injected with Tam or Oil at $7 \mathrm{dpi}$ (Oil, $527 \pm 159$ cells $/ \mathrm{mm}^{2}$; Tam, $414 \pm 36$ cells $/ \mathrm{mm}^{2}$; unpaired $t$ test, $t_{(4)}=0.694, p=0.525$ ) and at $90 \mathrm{dpi}$ (Oil, $780 \pm$ 27 cells $/ \mathrm{mm}^{2}$; Tam, $647 \pm 143$ cells $/ \mathrm{mm}^{2}$; unpaired $t$ test, $\left.t_{(4)}=0.915, p=0.412\right)$. We then analyzed the density of $\alpha 2$-subunit clusters on the cell body and the apical dendrite of $\mathrm{eGFP}^{+}$cells. We found a strong decrease in cluster density in Tam-injected mice compared with the control group already at $7 \mathrm{dpi}$ (cell body, $t_{(4)}=6.119, p=0.0036$; apical dendrite, $t_{(4)}=15.01, p<0.0001$; Fig. $\left.6 B, C\right)$. Similarly, we observed a decreased density of gephyrin clusters in the proximal portion of the apical dendrite of Tam mice (Oil, $0.169 \pm 0.016$ clusters $/ \mu \mathrm{m}$; Tam, $0.080 \pm 0.016$ clusters $/ \mu \mathrm{m} ; t_{(4)}=3.871, p=$ 0.018 ). Triple-immunofluorescence staining confirmed that these remaining gephyrin clusters were colocalized with the $\alpha 3$-subunit (data not shown). Accordingly, the density of $\alpha 3 /$ gephyrin clusters was similar in both groups (Fig. 6D) in the cell body $\left(t_{(4)}=1.186, p=0.30\right)$ and in the apical dendrite $\left(t_{(4)}=0.381, p=0.72\right)$, indicating that no compensation occurs, as in $\alpha 2$-FL mice.

We then investigated whether this early deletion of the $\alpha 2$-subunit impairs dendritic development similar to the situation in $\alpha 2$-FL mice. Measurements from $\mathrm{eGFP}^{+}$cells in Tam-injected mice showed reduced dendritic branching (Fig. $6 E$ ), with the number of terminal branches being significantly lower already at 7 dpi (Fig. $6 F ; t_{(4)}=5.712, p=0.0046$ ), a defect that persisted until 90 dpi (Fig. $6 F ; t_{(4)}=5.129, p=$ $0.0068)$. This reduction was also reflected in the Sholl analysis made at 90 dpi, revealing significantly reduced AUC (Fig. 6G; Oil, $366 \pm 7.7$; Tam, $\left.289 \pm 11.8 ; t_{(4)}=6.895, p=0.002\right)$, particularly at the $100-250 \mu \mathrm{m}$ portion from the soma. Spine density was also significantly decreased in Tam-treated mice at $7 \mathrm{dpi}($ Fig. $6 \mathrm{H})$, and this defect persisted at $90 \mathrm{dpi}\left(7 \mathrm{dpi}, t_{(4)}=\right.$ 11.44, $p=0.0003$; $90 \mathrm{dpi}, t_{(4)}=7.74, p=0.0015$; Fig. 6I,J). The reduced spine density was accompanied by a decreased number of PSD95 clusters in spines $t_{(4)}=12.02, p=0.0003$; Fig. $6 J, K)$. However, in contrast with $\alpha 2$-FL mice, we did not observe an increase in the density of PSD95 clusters along dendritic profiles. These data indicate that early depletion of the $\alpha 2$-subunit accelerates developmental alterations in newborn GCs but eventually results in structural defects that primarily overlap with those seen in $\alpha 2$-FL mice.

\section{Discussion}

In this study, we show that functional $\alpha 2-\mathrm{GABA}_{\mathrm{A}} \mathrm{Rs}$ are required for proper structural development of adult-born GCs and for the onset of sensory-dependent structural plasticity. Major deficits of GCs lacking $\alpha 2-\mathrm{GABA}_{\mathrm{A}} \mathrm{Rs}$ include the absence of spine/dendrite overproduction $\sim 30 \mathrm{dpi}$, persistence of glutamatergic synapses on the dendritic shaft, and an inability to adjust their morphology to sensory challenges. Similar observations were made when Gabra2 was inactivated early in neural stem cells or later in migrating neuroblasts. Our work demonstrates that early GABAergic synaptic transmission is an important determinant for the development and function of adult-generated $\mathrm{OB}$ interneurons.

Specificity and efficiency of $\alpha 2$-subunit deletion of GABA $\mathrm{A}_{\mathrm{A}} \mathrm{R}$ Adult-born GCs express $\mathrm{GABA}_{\mathrm{A}}$ Rs early in development and are responsive to GABAergic signals already in the neurogenic zone and in the RMS (Platel et al., 2008). Sixteen $\mathrm{GABA}_{\mathrm{A}} \mathrm{R}$ subunits are expressed in a time- and location-specific manner in the developing and adult brain (Laurie et al., 1992; Fritschy and Brünig, 2003). Because $G_{A B A} R$ subtypes have unique functional properties, they may differentially regulate distinct steps of adult neurogenesis (Duveau et al., 2011). In the SVZ-OB system, multiple $\mathrm{GABA}_{\mathrm{A}} \mathrm{R}$ subunits have been detected in neonatal neuroblasts (Stewart et al., 2002) and polysialylated neural cell adhesion molecule-positive progenitors derived from neurospheres (Nguyen et al., 2003). Adult GCs also express distinct $\mathrm{GABA}_{\mathrm{A}} \mathrm{Rs}$ mediating tonic and phasic inhibition. Here, we focused on $\alpha 2-$ 
$\mathrm{GABA}_{\mathrm{A}} \mathrm{Rs}$, which represent the majority of postsynaptic receptors expressed in GCs and are absent from mitral and tufted cells (Panzanelli et al., 2009). We silenced these receptors by two means. We injected a CreeGFP-encoding lentivirus into the RMS of adult $\alpha 2$-FL mice, and we used an eGFPencoding lentivirus in GLAST::creERT2 ${ }^{+/-}$ mice previously treated with Tam. We found that deletion of the $\alpha 2$-subunit occurs $\geq 3$ weeks after injection of the lentiviral vector. Therefore, in the first model (i.e., $\alpha 2$-FL mice), $\alpha 2-\mathrm{GABA}_{\mathrm{A}}$ Rs were removed only after newly formed GCs had already reached the $\mathrm{OB}$, thus avoiding potential compensatory mechanisms that could take place during earlier development. In the second approach, $\alpha 2-\mathrm{GABA}_{\mathrm{A}}$ Rs were deleted in adult neural stem cells (i.e., GLAST ${ }^{+}$ cells) before their final neuronal commitment. Remarkably, most of the observations made with the first model were validated by the second approach, thus ruling out any potential bias attributable to early GABAergic signaling that was preserved in developing GCs of $\alpha 2$-FL mice. It is also worth noting that, in both genetic models, the dramatic reduction of $\alpha 2-\mathrm{GABA}_{\mathrm{A}}$ Rs was not compensated by the $\alpha 3$-subunit, resulting in a severe reduction of the amplitude and frequency of spontaneous synaptic GABAergic events. As expected, however, the strongly decreased expression of $\mathrm{GABA}_{\mathrm{A}} \mathrm{Rs}$ correlated with reduced amplitude and frequency of spontaneous synaptic GABAergic events. These functional alterations were evident already at $14 \mathrm{dpi}$, preceding the loss of $\alpha 2$-subunit or gephyrin clusters seen morphologically. This discrepancy may reflect the greater sensitivity of electrophysiological analysis, probing not only synapse density but also the number of receptors active in each synapse and their functional properties. In addition, because the rise time of sIPSCs was unchanged after deleting the $\alpha 2$-subunit, we conclude that the downregulation of GABAergic currents is homogeneous between the somatic and dendritic compartments. The currents that remain in GCs of $\alpha 2$-FL mice have a kinetic profile consistent with $\mathrm{GABA}_{\mathrm{A}} \mathrm{Rs}$ containing the $\alpha 3$-subunit (Schofield et al., 2009). Notably, these small and slow currents were not sufficient to rescue the maturation of newborn GCs.

Despite these postsynaptic alterations and the loss of gephyrin clusters caused by Gabra2 inactivation, innervation by GABAergic terminals was not visibly affected. This finding is in line with previous studies showing that postsynaptic $\mathrm{GABA}_{\mathrm{A}} \mathrm{Rs}$ are not essential for inhibitory synaptogenesis (Panzanelli et al., 2011). Finally, in both experimental settings, Gabra2 inactivation did not affect GC survival (as assessed by quantifying the number of $\mathrm{eGFP}^{+}$cells in the GCL),

A

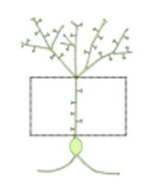

C

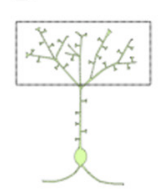

I
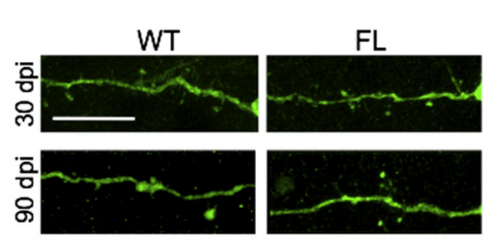

B
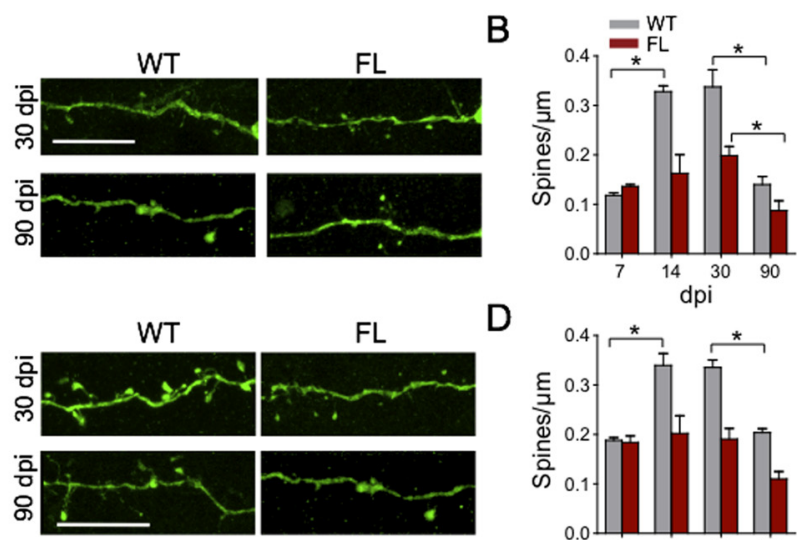

D
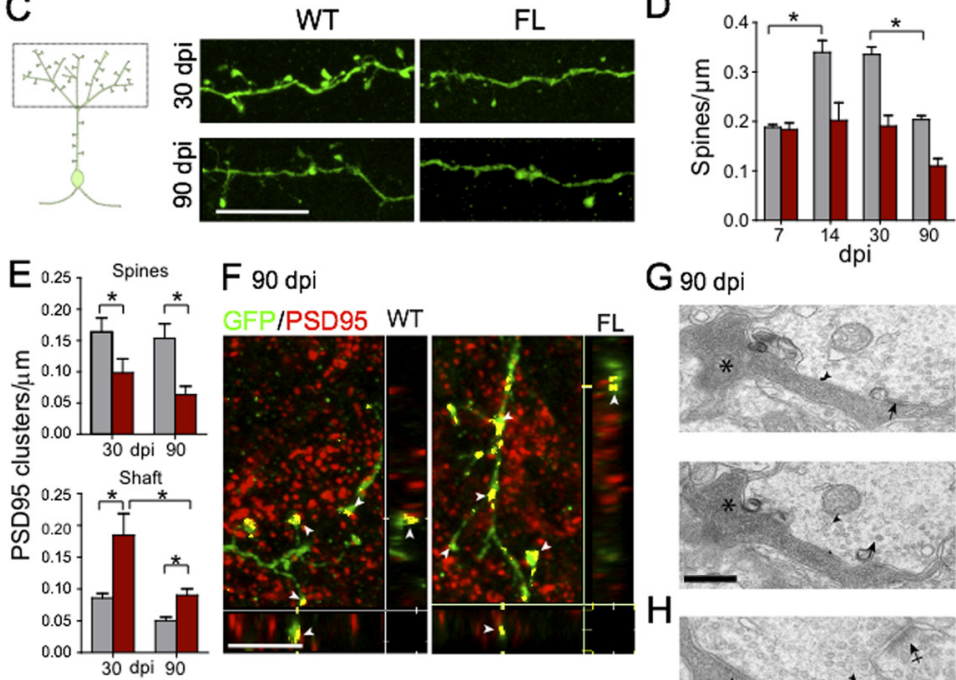

F 90 dpi
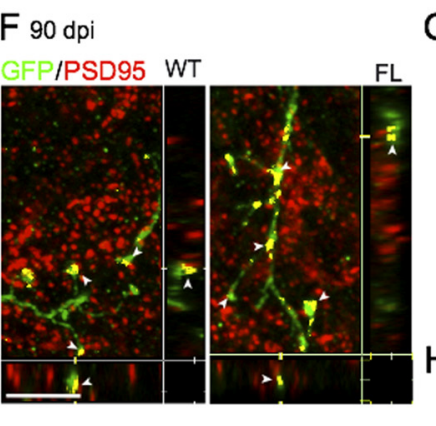

G $90 \mathrm{dpi}$
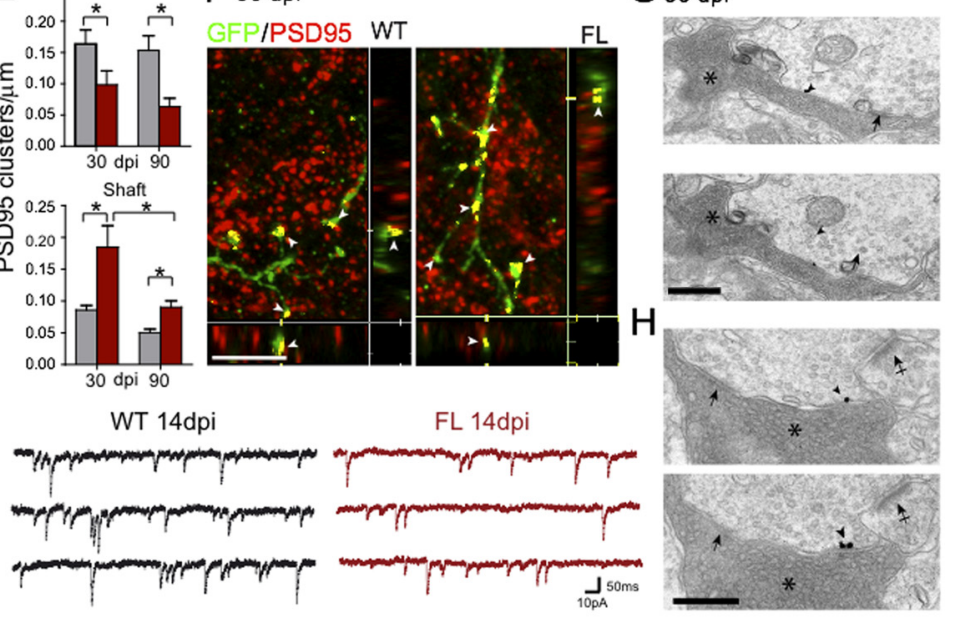

$\mathrm{H}$
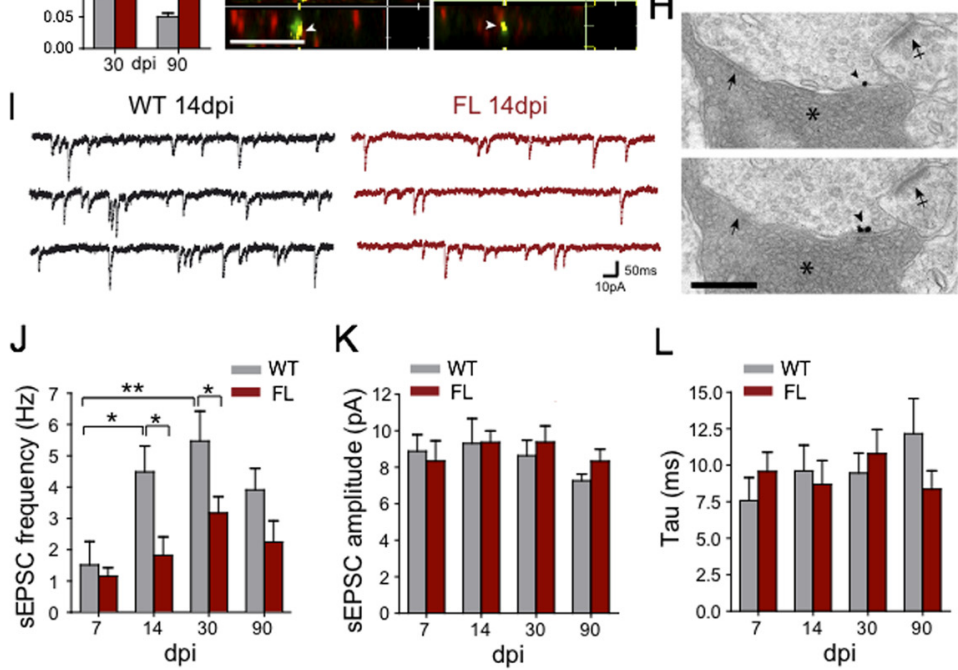

Figure 4. Altered excitatory inputs in newborn GCs from $\alpha 2$-FL mice. $\boldsymbol{A}, \boldsymbol{C}$, Representative images of dendritic spines on the apical dendrites of eGFP ${ }^{+}$cells of WT and $\alpha 2$-FL mice in the GCL $(\boldsymbol{A})$ and EPL ( $\boldsymbol{C}$ ) at 30 and 90 dpi. $\boldsymbol{B}, \boldsymbol{D}$, Quantification of spine density (mean \pm SEM) on apical dendrites in the GCL $(\boldsymbol{B})$ and EPL $(\boldsymbol{D})$; one-way ANOVA with posthoctests $\left({ }^{*} p<0.05\right.$; for general statistical analysis, see Table 7).E, Quantification of PSD95 clusters colocalized with eGFP on the spines and shaft of apical dendrites at 30 and $90 \mathrm{dpi} \mathrm{in} \mathrm{the} \mathrm{EPL} \mathrm{(mean} \pm$ SEM; ${ }^{*} p<0.05$, Bonferroni's post hoc test). $\boldsymbol{F}$, Images (3-D projection) depicting PSD95-immunoreactive clusters (red) on eGFP ${ }^{+}$spinelike structures and dendritic shafts in the EPL at 90 dpi in WT and $\alpha 2$-FL mice; colocalization is depicted in yellow (arrowheads). $\mathbf{G}, \boldsymbol{H}, \mathbf{D}$ Double immunoelectron microscopy for gephyrin (silver grains, arrowheads) and eGFP $\left(^{*}\right)$ in eGFP ${ }^{+} \mathrm{GCs}$ of $\alpha 2$-FL mice. Each pair of serial sections depicts an asymmetric (excitatory) synapse (arrow) formed by a mitral cell dendritic profile on an eGFP ${ }^{+} \mathrm{GC}$ dendrite profile, which in turn makes a gephyrin-positive (arrowhead) symmetric synapse on the same mitral cell profile. The crossed arrows in $\boldsymbol{H}$ point to an asymmetric synapse onto an eGFP' ${ }^{-}$spine profile. $I$, Representative traces of sEPSCs recorded at $-70 \mathrm{mV}$ at $14 \mathrm{dpi}$. $J-L$, Histograms of sEPSC frequency (hertz) (J), amplitude (picoamperes) (K), and decay time constant (milliseconds) ( $\boldsymbol{L}$ ) in GCs from WT and $\alpha 2$-FL mice (mean \pm SD). For statistical analysis, see Tables 3 and $4 B$; WT and $\alpha 2$-FL groups were compared by one-way ANOVA, followed by Bonferroni's post hoc tests $\left({ }^{*} p<0.05 ;{ }^{* *} p<0.01\right)$. Scale bars: $\boldsymbol{A}, \boldsymbol{C}, 5 \mu \mathrm{m} ; \boldsymbol{F}, 2 \mu \mathrm{m} ; \boldsymbol{G}, \boldsymbol{H}, 0.2 \mu \mathrm{m}$.

indicating that functional GABAergic synapses are dispensable for long-term survival of adult-born GCs.

Impaired dendritic and synaptic development in GCs with decreased GABAergic input

GABA is considered as a key actor at early stages of adult neurogenesis. In the SVZ, it reduces the number of proliferative neural 


\section{A}
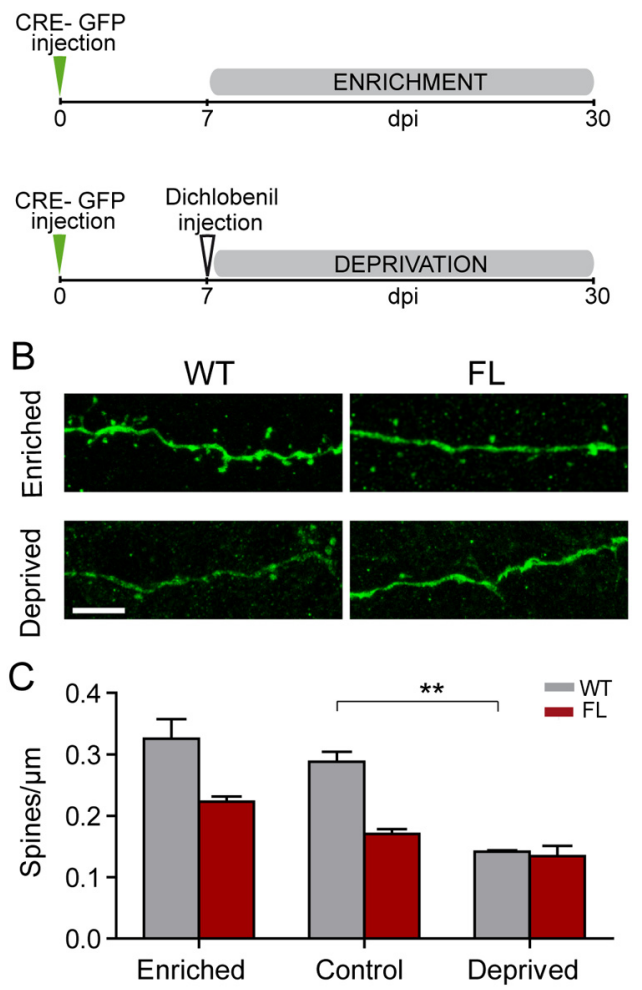

Figure 5. Effects of sensory stimulation and deprivation on spine development in newborn GCs. $A$, Schematic diagram of the experimental protocol used for olfactory enrichment or deprivation. Adult mice were injected in the SVZ with the Cre- eGFP lentivirus. One week after virus injection, mice were either exposed to enriched olfactory stimuli for 3 weeks or injected with dichlobenil for sensory deprivation. $\boldsymbol{B}$, Representative images of $\mathrm{eGFP}^{+}$spines on apical dendrites of newborn GCs in enriched (top row) and deprived (bottom row) WT and $\alpha 2$-FL mice. C, Quantification of spine density (mean \pm SEM) in the EPL of deprived and enriched mice (one-way ANOVA with post hoc tests; for statistical analysis, see Results; ${ }^{* *} p<0.01$ ). Scale bar, $2 \mu \mathrm{m}$.

stem cells via tonic activation of $\mathrm{GABA}_{\mathrm{A}}$ Rs (Liu et al., 2005). Similarly, GABAergic signaling controls neuroblast migration in the RMS via paracrine effects (Bolteus and Bordey, 2004; Ge et al., 2006; Platel et al., 2008). These early functions demonstrate that GABA spillover might provide important information to neural stem cells and migrating progenitors about the size of the population of neuroblasts already formed (Platel et al., 2007). However, although GABA controls these early developmental stages, the function of GABAergic signaling on the ensuing maturation of GCs has remained elusive.

We show here that reducing synaptic transmission mediated by $\alpha 2-\mathrm{GABA}_{\mathrm{A}} \mathrm{Rs}$ in developing GCs has detrimental effects on their structural maturation. Specifically, postsynaptic $\mathrm{GABA}_{\mathrm{A}} \mathrm{Rs}$ are required to control dendritic growth and spine formation after GCs have reached their final destination in the OB. During their maturation, adult-born GCs receive synaptic inputs from several distinct glutamatergic and GABAergic neurons (Whitman and Greer, 2009; Kelsch et al., 2010; Nissant and Pallotto, 2011). Furthermore, GC maturation is characterized by an initial overproduction of spines and glutamatergic synapses, followed by a phase of synaptic pruning (Whitman and Greer, 2007), likely corresponding to a phase of maturation during which synapses are refined by activity-dependent mechanisms. Strikingly, this window of increased plasticity was suppressed in newborn GCs lacking the $\alpha 2$-subunit, in which dendritic length and spine density remained constant during the entire developmental period. Therefore, functional $\alpha 2-\mathrm{GABA}_{\mathrm{A}} \mathrm{Rs}$ at afferent GABAergic synapses are essential for proper synaptic integration of adultborn GCs. This conclusion supports another study showing that blockade of $\mathrm{GABA}_{\mathrm{A}}$ Rs triggered a rapid stabilization of new dendritic segments in acute $\mathrm{OB}$ slices (Gascon et al., 2006). Of particular interest is the fact that the reduced spinogenesis in mutant GCs was accompanied by a persistence of PSD95 clusters on dendritic shafts up to 90 dpi. We showed previously in WT mice that dendro-dendritic synapses initially form on the shaft of GC dendrites, before being transferred to spines (Panzanelli et al., 2009). Our present results indicate that this morphological rearrangement is disrupted in mutant GCs, most likely reflecting an intrinsic deficit in spine formation.

The mechanisms by which $\mathrm{GABA}_{\mathrm{A}} \mathrm{R}$ activation contributes to regulate dendritic development and glutamatergic synaptogenesis are unclear. One possibility is that GABAergic transmission is linked to signaling cascades controlling multiple aspects of neuronal development. Indeed, in the dentate gyrus, GABA supports neuronal maturation by increasing the expression of transcription factors and by regulating CREB-dependent transcriptional events (Tozuka et al., 2005). At the dendritic level, GABAergic activity may be essential for regulating local activity patterns and calcium transients that are involved in the stabilization and maturation of axo-dendritic contacts in hippocampal neurons (Lohmann and Bonhoeffer, 2008).

The present results also reveal apparent differences in the role of $\alpha 2-\mathrm{GABA}_{\mathrm{A}}$ Rs during maturation of adult-born GCs in the OB and in the dentate gyrus (Duveau et al., 2011). In the latter study, analysis of both global Gabra2 inactivation and single-cell deletion with $\mathrm{Cre}^{+}$viruses demonstrated normal initial dendritic growth and spine formation, followed by excessive dendritic pruning in 4- to 6-week-old cells. This dendritic pruning was prevented by pharmacologically reducing glutamatergic synaptogenesis, suggesting that it either was a homeostatic mechanism to preserve inhibitory-excitatory balance in newborn neurons or it was a consequence of activity-dependent dendritic development. This phenotype is relatively mild compared with the one reported here in OB GCs and likely reflects the fact that $\alpha 1-$ $\mathrm{GABA}_{\mathrm{A}} \mathrm{Rs}$ are primarily preserved in the dentate gyrus during Gabra2 inactivation, implying a less dramatic impairment of postsynaptic GABAergic function. These studies collectively indicate that functional $\alpha 2-\mathrm{GABA}_{\mathrm{A}} \mathrm{Rs}$ are required for normal structural development and functional maturation of adult-born neurons in the brain.

\section{Absence of activity-dependent regulation in new neurons lacking GABAergic input}

Our study supports an important role of GABAergic synaptic transmission for the activity-dependent selection of synaptic connectivity that occurs during a critical window of maturing GCs (Lledo and Gheusi, 2003). Because the OB circuit is only one synapse away from the external world, we sought to examine the potential role for GABA in mediating circuit remodeling induced by sensory experience (Saghatelyan et al., 2005). When challenging the degree of sensory inputs to the $\mathrm{OB}$, we found that neither sensory enrichment nor sensory deafferentation caused significant changes in spine density in GCs lacking $\alpha 2-\mathrm{GABA}_{\mathrm{A}}$ Rs. This observation indicates that functional afferent GABAergic synaptic transmission is required for structural adaptations occurring in adult-born GCs 
A

$$
\text { Glast::creERT2 }{ }^{+/-} \text {- Gabra2 FL }
$$

B $7 \mathrm{dpi}$
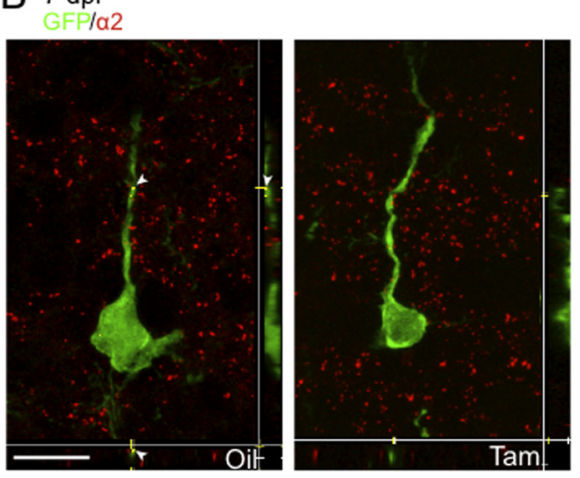
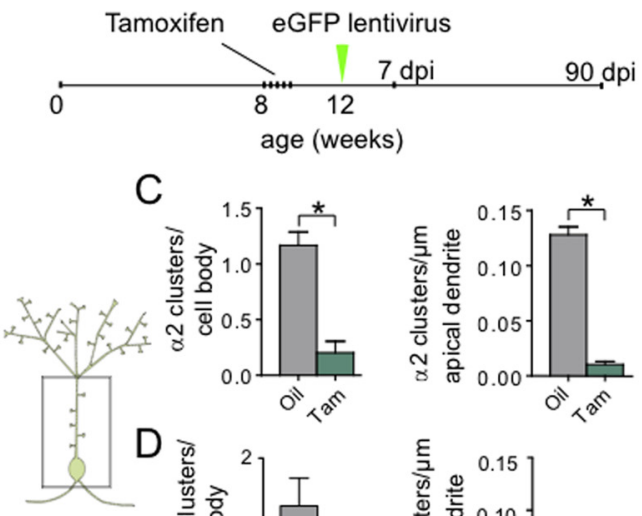

C
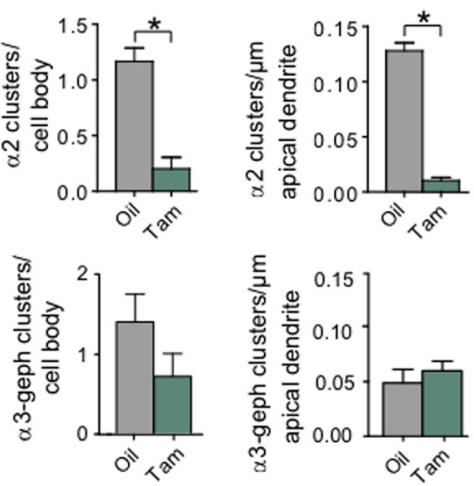

$\mathrm{E}$
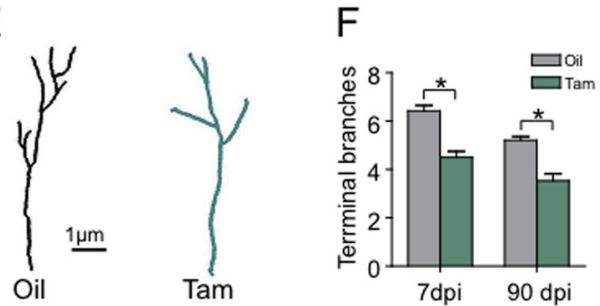

G
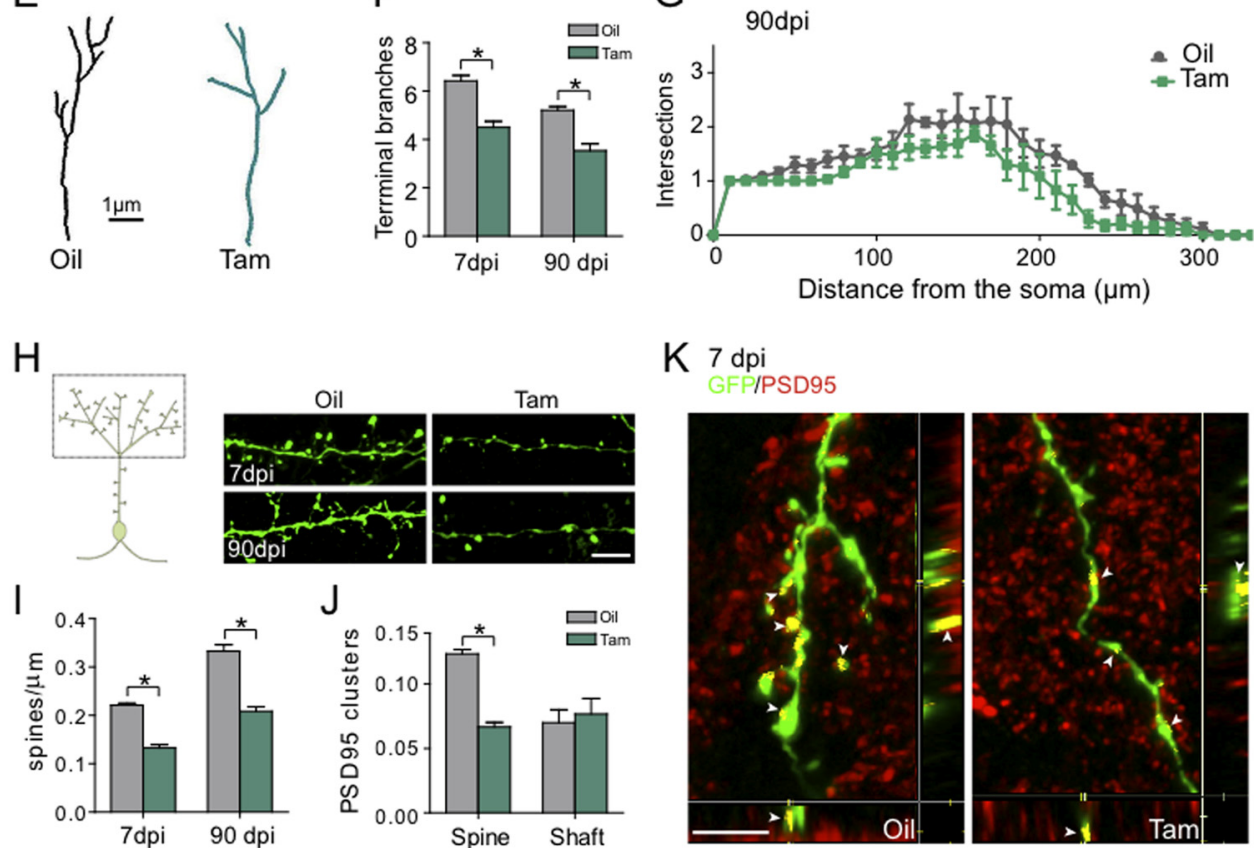

K 7 dpi
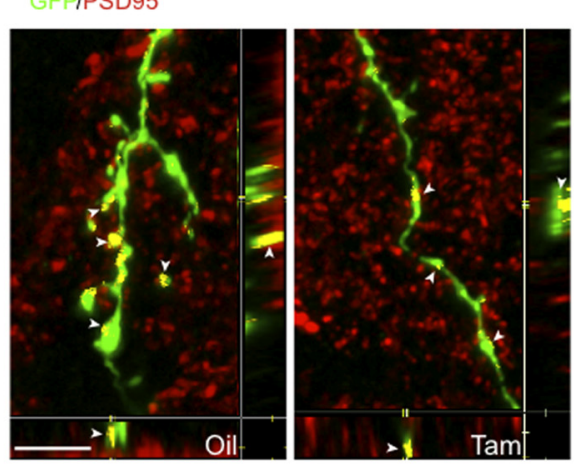

Figure 6. Effects of early inactivation of Gabra2 in progenitor cells. A, Schematic diagram of the experimental design: 8-week-old GLAST mice were injected with Tam or 0il once a day for 5 d. At 12 weeks of age, mice were injected with the eGFP lentivirus in the SVZ; they were then analyzed at 7 or $90 \mathrm{dpi}$. B, Representative images (3-D projections) showing $\alpha 2$-subunit clusters (red) in newborn GCs of GLAST mice (Oil- and Tam-injected) after $7 \mathrm{dpi}$, confirmed by colocalization analysis (yellow; arrowheads). Note the loss of $\alpha 2$-subunit clusters in eGFP ${ }^{+}$cells of Tam-injected mice. C, Quantification of $\alpha 2$-subunit clusters (mean \pm SEM) in Tam-injected (green) and Oil-injected (gray) mice at $7 \mathrm{dpi}$ in cell body and in the apical dendrite. D, Quantification of $\alpha 3$-subunit and gephyrin clusters (mean \pm SEM) in the cell body and apical dendrite of Tam-injected (green) and Oil-injected (gray) mice at $7 \mathrm{dpi}$, as determined by triple fluorescence staining. There was no significant difference in the density of $\alpha 3$-subunit clusters colocalized with gephyrin $(\alpha 3 / \mathrm{geph})$ in either compartment. $\boldsymbol{E}$, Representative drawings of eGFP ${ }^{+}$cells used for Sholl analysis in Oil-injected (gray) and Tam-injected (green) GLAST mice. $\boldsymbol{F}$, Histogram of the number of terminal dendritic branches (mean \pm SEM) showing a reduction at 7 and 90 dpi in Tam-injected mice. $\boldsymbol{G}$, Sholl analysis comparison between 0il-injected mice (gray line) and Tam-injected mice (green line) at 7 dpi illustrating the reduced dendritic complexity in Tam mice. $\boldsymbol{H}$, Representative images of $\mathrm{eGFP}^{+}$dendritic spines in the EPL of Oil- and Tam-injected mice at 7 and 90 dpi. I, J, Histograms of spine density in the EPL (mean \pm SEM) at 7 and 90 dpi and PSD95 cluster density on spines and dendritic shafts (clusters per micrometer of dendrite). The decrease of spines correlates with that of PSD95 clusters in Tam-injected mice. Two-tailed Student's $t$ test; ${ }^{*} p<0.05$. $\boldsymbol{K}$, Immunofluorescence staining for PSD95 clusters (red) colocalized with eGFP ${ }^{+}$spine-like structures and dendritic shafts in the EPL after $7 \mathrm{dpi}$ in Oil-injected control and Tam-injected mice; arrowheads point to sites of colocalization (yellow). Scale bars: $\boldsymbol{B}, 10 \mu \mathrm{m} ; \boldsymbol{H}, 2 \mu \mathrm{m} ; \boldsymbol{I}, 1 \mu \mathrm{m}$.

as a response to sensory stimulation during the phase of dendritic/spine exuberance. Therefore, GABAergic transmission in adult-generated GCs may set appropriate levels of local inhibition to support a critical period of plasticity, as also shown in other sensory systems (Hensch, 2005). Additional studies will have to explore whether the crucial contribution of $\alpha 2-\mathrm{GABA}_{\mathrm{A}}$ Rs to activity-dependent plasticity depends on the depolarizing or hyperpolarizing action of GABA.

\section{References}

Alonso M, Ortega-Pérez I, Grubb MS, Bourgeois JP, Charneau P, Lledo PM (2008) Turning astrocytes from the rostral migratory stream into neurons: a role for the olfactory sensory organ. J Neurosci 28: 11089-11102.

Altman J (1969) Autoradiographic and histological studies of postnatal neurogenesis. IV. Cell proliferation and migration in the anterior forebrain, with special reference to persisting neurogenesis in the olfactory bulb. J Comp Neurol 137:433-457. 
Alvarez-Buylla A, Garcia-Verdugo JM (2002) Neurogenesis in adult subventricular zone. J Neurosci 22:629-634.

Bolteus AJ, Bordey A (2004) GABA release and uptake regulate neuronal precursor migration in the postnatal subventricular zone. J Neurosci 24:7623-7631.

Chang YC, Gottlieb DI (1988) Characterization of the proteins purified with monoclonal antibodies to glutamic acid decarboxylase. J Neurosci 8:2123-2130.

Duveau V, Laustela S, Barth L, Gianolini F, Vogt KE, Keist R, Chandra D, Homanics GE, Rudolph U, Fritschy JM (2011) Spatiotemporal specificity of $\mathrm{GABA}_{\mathrm{A}}$ receptor-mediated regulation of adult hippocampal neurogenesis. Eur J Neurosci 34:362-373.

Fritschy JM, Brünig I (2003) Formation and plasticity of GABAergic synapses: physiological mechanisms and pathophysiological implications. Pharmacol Ther 98:299-323.

Fritschy JM, Mohler H (1995) $\mathrm{GABA}_{\mathrm{A}}$-receptor heterogeneity in the adult rat brain: differential regional and cellular distribution of seven major subunits. J Comp Neurol 359:154-194.

Gascon E, Dayer AG, Sauvain MO, Potter G, Jenny B, De Roo M, Zgraggen E, Demaurex N, Muller D, Kiss JZ (2006) GABA regulates dendritic growth by stabilizing lamellipodia in newly generated interneurons of the olfactory bulb. J Neurosci 26:12956-12966.

Ge S, Goh EL, Sailor KA, Kitabatake Y, Ming GL, Song H (2006) GABA regulates synaptic integration of newly generated neurons in the adult brain. Nature 439:589-593.

Grubb MS, Nissant A, Murray K, Lledo PM (2008) Functional maturation of the first synapse in olfaction: development and adult neurogenesis. J Neurosci 28:2919-2932.

Hensch TK (2005) Critical period plasticity in local cortical circuits. Nat Rev Neurosci 6:877-888.

Holderith NB, Shigemoto R, Nusser Z (2003) Cell type-dependent expression of HCN1 in the main olfactory bulb. Eur J Neurosci 18:344-354.

Katagiri H, Pallotto M, Nissant A, Murray K, Sassoè-Pognetto M, Lledo PM (2011) Dynamic development of the first synapse impinging on adultborn olfactory neurons. Neural Syst Circuits 1:6.

Kelsch W, Lin CW, Lois C (2008) Sequential development of synapses in dendritic domains during adult neurogenesis. Proc Natl Acad Sci U S A 105:16803-16808

Kelsch W, Lin CW, Mosley CP, Lois C (2009) A critical period for activitydependent synaptic development during olfactory bulb adult neurogenesis. J Neurosci 29:11852-11858.

Kelsch W, Sim S, Lois C (2010) Watching synaptogenesis in the adult brain. Annu Rev Neurosci 33:131-149.

Kempermann G, Jessberger S, Steiner B, Kronenberg G (2004) Milestones of neuronal development in the adult hippocampus. Trends Neurosci $27: 447-452$

Kollo M, Holderith N, Antal M, Nusser Z (2008) Unique clustering of A-type potassium channels on different cell types of the main olfactory bulb. Eur J Neurosci 27:1686-1699.

Laurie DJ, Wisden W, Seeburg PH (1992) The distribution of thirteen $\mathrm{GABA}_{\mathrm{A}}$ receptor subunit mRNAs in the rat brain. III. Embryonic and postnatal development. J Neurosci 12:4151-4172.

Liu X, Wang Q, Haydar TF, Bordey A (2005) Nonsynaptic GABA signaling in postnatal subventricular zone controls proliferation on GFAPexpressing progenitors. Nat Neurosci 8:1179-1187.

Lledo PM, Gheusi G (2003) Olfactory processing in a changing brain. Neuroreport 14:1655-1663.

Lledo PM, Alonso M, Grubb MS (2006) Adult neurogenesis and functional plasticity in neuronal circuits. Nat Rev Neurosci 7:179-193.

Lohmann C, Bonhoeffer T (2008) A role for local calcium signaling in rapid synaptic partner selection by dendritic filopodia. Neuron 59:253-260.

Ming GL, Song H (2011) Adult neurogenesis in the mammalian brain: significant answers and significant questions. Neuron 70:687-702.

Mori T, Tanaka K, Buffo A, Wurst W, Kühn R, Götz M (2006) Inducible gene deletion in astroglia and radial glia-a valuable tool for functional and lineage analysis. Glia 54:21-34.

Nguyen L, Malgrange B, Breuskin I, Bettendorff L, Moonen G, Belachew S,
Rigo JM (2003) Autocrine/paracrine activation of the $\mathrm{GABA}_{\mathrm{A}}$ receptor inhibits the proliferation of neurogenic polysialylated neural cell adhesion molecule-positive $\left(\mathrm{PSA}^{-\mathrm{NCAM}^{+}}{ }^{+}\right.$) precursor cells from postnatal striatum. J Neurosci 23:3278-3294.

Nissant A, Pallotto M (2011) Integration and maturation of newborn neurons in the adult olfactory bulb-from synapses to function. Eur J Neurosci 33:1069-1077.

Nissant A, Bardy C, Katagiri H, Murray K, Lledo PM (2009) Adult neurogenesis promotes synaptic plasticity in the olfactory bulb. Nat Neurosci 12:728-730.

Panzanelli P, Bardy C, Nissant A, Pallotto M, Sassoè-Pognetto M, Lledo PM, Fritschy JM (2009) Early synapse formation in developing interneurons of the adult olfactory bulb. J Neurosci 29:15039-15052.

Panzanelli P, Gunn BG, Schlatter MC, Benke D, Tyagarajan SK, Scheiffele P, Belelli D, Lambert JJ, Rudolph U, Fritschy JM (2011) Distinct mechanisms regulate GABAA receptor and gephyrin clustering at perisomatic and axoaxonic synapses on CA1 pyramidal cells. J Physiol 589:4959-4980.

Platel JC, Lacar B, Bordey A (2007) GABA and glutamate signaling: homeostatic control of adult forebrain neurogenesis. J Mol Histol 38:602-610.

Platel JC, Dave KA, Bordey A (2008) Control of neuroblast production and migration by converging GABA and glutamate signals in the postnatal forebrain. J Physiol 586:3739-3743.

Rochefort C, Gheusi G, Vincent JD, Lledo PM (2002) Enriched odor exposure increases the number of newborn neurons in the adult olfactory bulb and improves odor memory. J Neurosci 22:2679-2689.

Saghatelyan A, Roux P, Migliore M, Rochefort C, Desmaisons D, Charneau P, Shepherd GM, Lledo PM (2005) Activity-dependent adjustments of the inhibitory network in the olfactory bulb following early postnatal deprivation. Neuron 46:103-116.

Schneider Gasser EM, Straub CJ, Panzanelli P, Weinmann O, SassoèPognetto M, Fritschy JM (2006) Immunofluorescence in brain sections: simultaneous detection of presynaptic and postsynaptic proteins in identified neurons. Nat Protoc 1:1887-1897.

Schofield CM, Kleiman-Weiner M, Rudolph U, Huguenard JR (2009) A gain in $\mathrm{GABA}_{\mathrm{A}}$ receptor synaptic strength in thalamus reduces oscillatory activity and absence seizures. Proc Natl Acad Sci U S A 106:7630-7635.

Shepherd GM, Chen WR, Willhite D, Migliore M, Greer CA (2007) The olfactory granule cell: from classical enigma to central role in olfactory processing. Brain Res Rev 55:373-382.

Stewart RR, Hoge GJ, Zigova T, Luskin MB (2002) Neural progenitor cells of the neonatal rat anterior subventricular zone express functional $\mathrm{GABA}_{\mathrm{A}}$ receptors. J Neurobiol 50:305-322.

Stone D, Grillo M, Margolis F, Joh T, Baker H (1991) Differential effect of functional olfactory bulb deafferentation on tyrosine hydroxylase and glutamic acid decarboxylase messenger RNA levels in rodent juxtaglomerular neurons. J Comp Neurol 311:223-233.

Tozuka Y, Fukuda S, Namba T, Seki T, Hisatsune T (2005) GABAergic excitation promotes neuronal differentiation in adult hippocampal progenitor cells. Neuron 47:803-815.

Vedin V, Slotnick B, Berghard A (2004) Zonal ablation of the olfactory sensory neuroepithelium of the mouse: effects on odorant detection. Eur J Neurosci 20:1858-1864.

Waclaw RR, Allen ZJ 2nd, Bell SM, Erdélyi F, Szabó G, Potter SS, Campbell K (2006) The zinc finger transcription factor Sp8 regulates the generation and diversity of olfactory bulb interneurons. Neuron 49:503-516.

Whitman MC, Greer CA (2007) Synaptic integration of adult-generated olfactory bulb granule cells: basal axodendritic centrifugal input precedes apical dendrodendritic local circuits. J Neurosci 27:9951-9961.

Whitman MC, Greer CA (2009) Adult neurogenesis and the olfactory system. Prog Neurobiol 89:162-175.

Witschi R, Punnakkal P, Paul J, Walczak JS, Cervero F, Fritschy JM, Kuner R, Keist R, Rudolph U, Zeilhofer HU (2011) Presynaptic $\alpha 2-\mathrm{GABA}_{\mathrm{A}}$ receptors in primary afferent depolarization and spinal pain control. J Neurosci 31:8134-8142.

Yamaguchi M, Mori K (2005) Critical period for sensory experiencedependent survival of newly generated granule cells in the adult mouse olfactory bulb. Proc Natl Acad Sci U S A 102:9697-9702. 